\title{
KINETICS AND MECHANISM OF THE NICKEL ELECTRODE--II. ACID SOLUTIONS CONTAINING A HIGH CONCENTRATION OF SULPHATE AND NICKEL IONS*
}

\author{
J. R. Vilche and A. J. ARvía \\ Instituto de Investigationes Fisicoquimicas Teóricas y Aplicadas, Sucursal 4, Casilla de Correo 16, \\ 1900 La Plata, Argentina
}

\begin{abstract}
The kinetics of the $\mathrm{Ni}$ electrode in acid solutions with a high sulphate and nickel ion concentration has been investigated in the range of $25-75^{\circ} \mathrm{C}$. The active dissolution and the passive regions and the active-passive transition phenomena have been studied employing different potential perturbation techniques using both still and stirred solutions.

Two electrochemical processes are competing within the prepassive film potential region, namely, the active $\mathrm{Ni}$ dissolution to $\mathrm{Ni}(\mathrm{II})$ ions and the $\mathrm{Ni}(\mathrm{OH})_{2}$ film formation. Nickel passivation is explained by reaction pathways involving successive electrochemical and chemical steps implying the occurrence of hydroxo- and oxo-species as reactions intermediates. The advanced mechanism is based upon a positively charged Ni surface structure and attributes the onset of the complete passivity to a particular surface oxide species.
\end{abstract}

\section{INTRODUCTION}

THE ANODIC behaviour of $\mathrm{Ni}$ in acid electrolytes is very complex and depends strongly on the metal purity, on its crystallographic characteristics, on the solution composition and on the type of perturbation applied to the metal/solution interface as it can be concluded from the various reviews already published on the subject. ${ }^{1-3}$ Thus, polycristalline $\mathrm{Ni}$ anodes in the presence of aggressive ions such as $\mathrm{Cl}$ - ions, dissolve anodically and, depending on the applied potential, localized corrosion takes place ${ }^{4-9}$, while in solutions containing either $\mathrm{H}_{2} \mathrm{SO}_{4}$ or $\mathrm{HClO}_{4}$ the anodic potentiostatic current/potential curve of $\mathrm{Ni}$ exhibits a region of active dissolution at low anodic potentials and a passivation region because of the formation of insoluble substances on the surface at high anodic potentials. ${ }^{10-15}$ Both processes are strongly influenced by the type of anions predominating in the solution composition. ${ }^{16,17}$

In many previous studies $\mathrm{H}_{2} \mathrm{SO}_{4}$ has been employed as electrolyte because due to weak adsorption of the anion its influence on the anodic process could be neglected. But in spite of those works there is still disagreement concerning the potential region where the $\mathrm{Ni}$ dissolution takes place and the metal enters into the passive state. Certainly the reported information obtained with plain $\mathrm{H}_{2} \mathrm{SO}_{4}$ solutions is not completely coincident. This is probably due to various concurrent facts. For example, the surface state of the metal and the composition of the solution change during the electrochemical measurements and the perturbation conditions of the metal/solution interface are therefore different. A critical analysis of the available experimental

*Manuscript received 4 February 1977; in revised form 30 June 1977. 


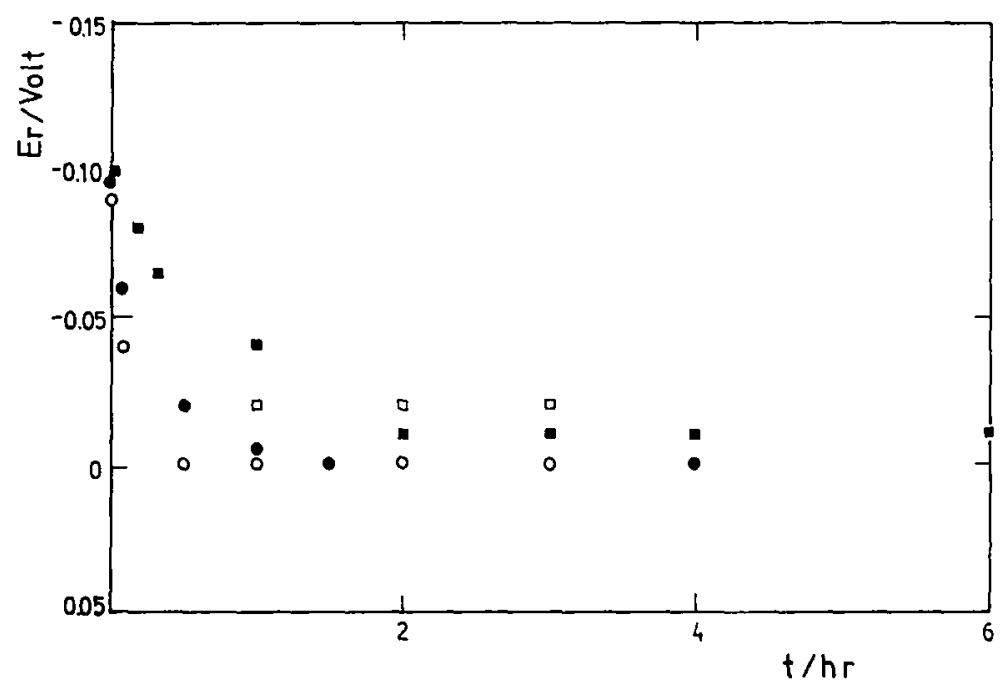

FiG. 1. Time dependence of the rest potential; Solution $\mathrm{A}, 25^{\circ} \mathrm{C},(\mathrm{O})$ freshly polished electrode, $(\bullet)$ the same electrode after a repetitive triangular potential sweep between -0.38 and $0.37 \mathrm{~V}$; Solution $\mathrm{B}, 50^{\circ} \mathrm{C}$, ([) freshly polished electrode, $(\square)$ the same electrode after $90 \mathrm{~min}$ at $-0.14 \mathrm{~V}$.

results indicates that the various reaction mechanisms advanced for the Ni electrode in acid solutions are not entirely consistent.

The present report is concerned with the study of $\mathrm{Ni}$ anodes in solutions containing $\mathrm{NiSO}_{4}$ and $\mathrm{H}_{2} \mathrm{SO}_{4}$. Preliminary results showed that the anodic potentiodynamic polarization of $\mathrm{Ni}$ results in complex $E / I$ displays from which a straightforward mechanistic interpretation is not always feasible. ${ }^{18}$ The situation, however, is reasonably improved when the solution composition is kept practically constant and the perturbation conditions are systematically changed. Then the results derived from the different experiments become more reliable for postulating a more general reaction model of the electrochemical processes of $\mathrm{Ni}$ in acid solutions covering both the active and passive regions as well as the transition between them.

\section{EXPERIMENTAL METHOD}

The Pyrex-glass electrolysis cell consists of three compartments separated by means of grade G-4 fritted glass discs. The volume of electrolyte in the working electrode compartment is $c a .0 .3 \mathrm{l}$. The Luggin-Haber capillary tip is located at $0.1 \mathrm{~cm}$ of the working electrode surface. A saturated calomel electrode properly shielded is used as reference $\left(E_{I I}=0.241 \mathrm{~V}\right.$ at $\left.25^{\circ} \mathrm{C}\right)$. The electrode potentials are referred to the NHE. The counter electrode is a large area Pt sheet.

Two different working electrodes are employed. One of them consists of a static Ni wire $0.5 \mathrm{~mm}$ dia., Johnson, Matthey Chemical Ltd, specpure quality) with the following impurities in ppm: $\mathrm{Fe}, 5 ; \mathrm{Cu}, 2 ; \mathrm{Si}, 2 ; \mathrm{Mg}, 1$ and $\mathrm{Al}, \mathrm{Ca}$, and $\mathrm{Ag}<1$. The wire electrode $\left(0.5 \mathrm{~cm}^{2}\right)$ is supported with a PTFE holder. A Ni rotating disc electrode is also employed. It is made by coaxially inserting a $2.8 \mathrm{~mm}$ dia. Ni rod into a $15 \mathrm{~mm}$ dia. PTFE cylinder. The electrode is mounted in the r.d.e. device. ${ }^{10}$

The following electrolytic solutions are employed: $1 \mathrm{~N} \mathrm{NiSO}_{4}+0.05 \mathrm{~N} \mathrm{H}_{2} \mathrm{SO}_{4}, \mathrm{pH}=1.75 \pm$ 0.05 (solution $\mathrm{A}$ ) and $1 \mathrm{~N} \mathrm{NiSO}_{4}+0.5 \mathrm{~N} \mathrm{H}_{2} \mathrm{SO}_{4}, \mathrm{pH}=0.70 \pm 0.05$ (solution $\mathrm{B}$ ) which are prepared from twice distilled water and p.a. Merck chemicals.

Experiments are run under $\mathrm{N}_{2}$ gas saturation at 25,50 and $75( \pm 0.05)^{\circ} \mathrm{C}$ using the different linear potential sweep techniques ${ }^{10}$ coupled with the r.d.e. technique. 


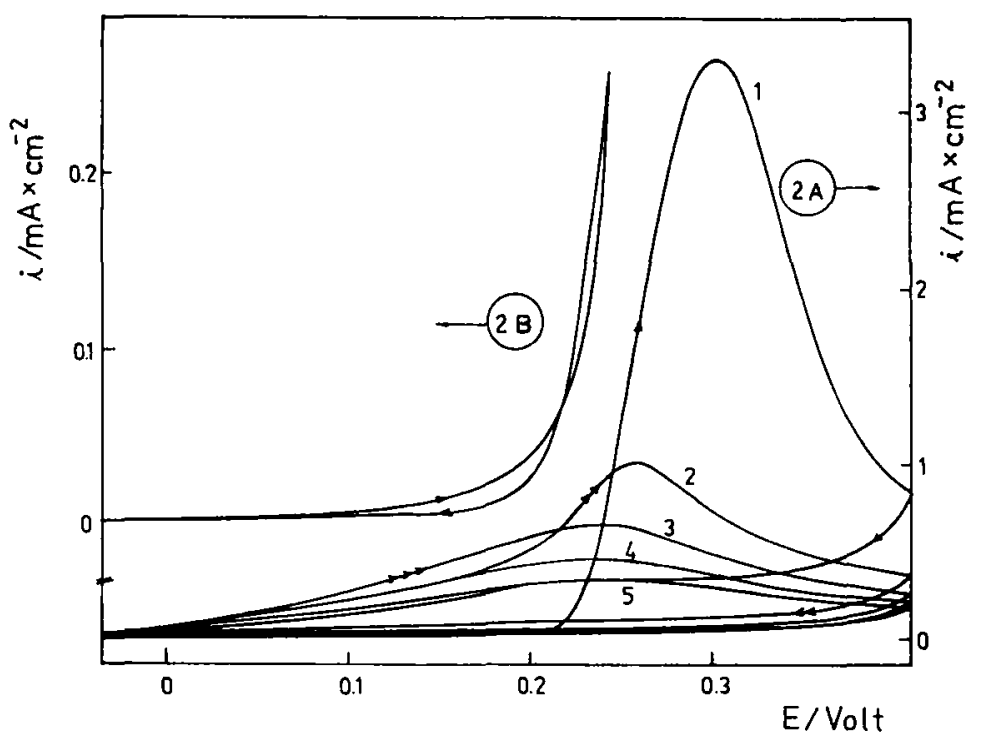

FIG. 2. $E / I$ displays obtained with symmetrical triangular potential seeps at $0.5 \mathrm{~V} / \mathrm{min}$. Solution $\mathrm{A}, 25^{\circ} \mathrm{C}$; (2A) potential scan between -0.025 and $0.415 \mathrm{~V} ;(2 \mathrm{~B})$ first potential scan between -0.035 and $0.235 \mathrm{~V}$.

\section{EXPERIMENTAL RESULTS}

\section{The rest potential}

After immersion of the freshly polished electrodes in the aqueous solutions the potential of the metal/solution interface changes initially very rapidly to attain after 30 min a value, $E_{r}$, which remains stable within $1 \mathrm{mV}$ at least for several hours (Fig. 1). At a constant $\mathrm{Ni}(\mathrm{II})$ ion concentration and practically constant ionic strength, the rest potential depends on $\mathrm{pH}$ according to a linear $E_{r} / \mathrm{pH}$ relationship with a slope equal to $-2.303(R T / 2 F)$.

\section{The potentiodynamic runs with still solutions}

Each experiment, unless stated otherwise is initiated from an $E_{r}$ value which remains constant for at least $1 \mathrm{~h}$, using a freshly prepared solution. Repetitive triangular potential sweeps at $0.5 \mathrm{~V} / \mathrm{min}$ between -0.035 and $+0.415 \mathrm{~V}(\Delta E=0.450 \mathrm{~V})$ with solution $A$ at $25^{\circ} \mathrm{C}$ and with a recently polished electrode, whose rest potential is $E_{r}=0.000 \pm 0.010 \mathrm{~V}$, exhibits an $E / I$ contour which changes during cycling (Fig. 2A). The first display shows an anodic current peak at $0.310 \mathrm{~V}$ (peak $\mathrm{D}$ ), and its returning halfcycle presents a current plateau involving a current much smaller than that of the anodic scan but extending towards a potential region where a negligible current is recorded during the anodic scan. The current height decreases in the following displays and the current peak shifts towards more cathodic potentials. Apparently a small anodic current peak is observed in the potential region between 0.05 and $0.15 \mathrm{~V}$. During the successive cycling the current of the returning halfcycle tend to zero. However, during the repetitive cycling there is an anodic current at $E_{r}$.

When the anodic potential limit is closer to the potential of current peak I 


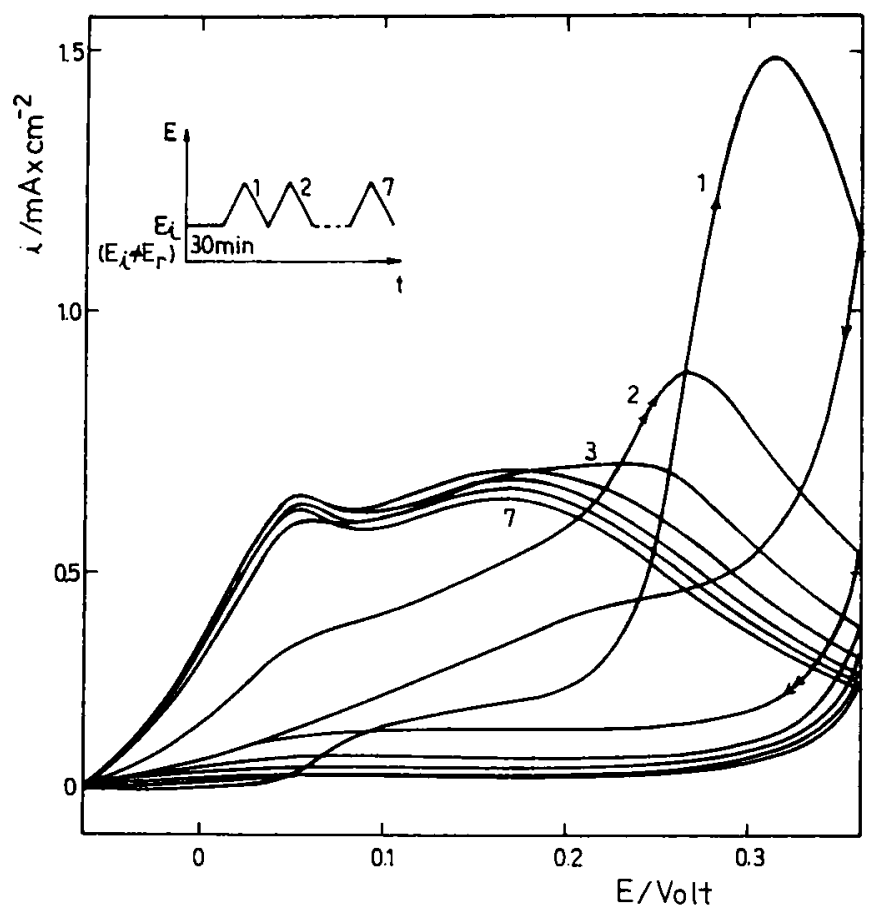

FIG. 3. $E / I$ display obtained under the conditions indicated in Fig. 2, but after keeping the electrode at $-0.065 \mathrm{~V}$ during $30 \mathrm{~min}$.

(Fig. 2B), the anodic current in the returning halfcycle is definitely larger than during the initial halfcycle and the crossing of the $E / I$ profiles occurs at more negative potentials.

The successive changes of the $E / I$ profiles during potential cycling are very sensitive to the initial potential $\left(E_{i} \neq E_{r}\right)$ and to the limits of both the anodic and cathodic potentials (Fig. 3). When $E_{i}=-0.065 \mathrm{~V}$ and the anodic limit is lower than in Fig. 2(A), the first anodic scan exhibits now a current plateau in the $0.1-0.2 \mathrm{~V}$ potential range which is not present when $E_{i}=E_{r}$, and the de-activation during the returning halfcycle occurs then at $c a .0 .22 \mathrm{~V}$, although the anodic current is then larger than that observed during the anodic scan. The anodic current peak I decreases during the cycling and after the third cycle two anodic current peaks predominate at $c a .0 .055$ and $0.170 \mathrm{~V}$. The successive returning scans exhibit a current plateau which decreases when, $n$, the number of cycles increases and approaches a null net current when $\left(E_{t}\right)_{t=0}$ is reached. The $E / I$ contours remain nearly unchanged after the 4th cycle. In this potential range, when, $v$, the scan rate decreases the anodic scans exhibit essentially the same features already described.

If the potential sweep extends up to $0.45 \mathrm{~V}$ (Fig. 4), the initial scan at $0.05 \mathrm{~V} / \mathrm{min}$ reveals the occurrence of a new anodic current contribution on the right side of current peak $I$ and the returning scan involves a broad and complex $E / I$ contour with a defined current peak at $0.025 \mathrm{~V}$ and a clear net current at $E_{r}$. The null current in this case is reached at a more negative potential, possibly closer to $\left(E_{i}\right)_{t=0}$. Only an anodic 


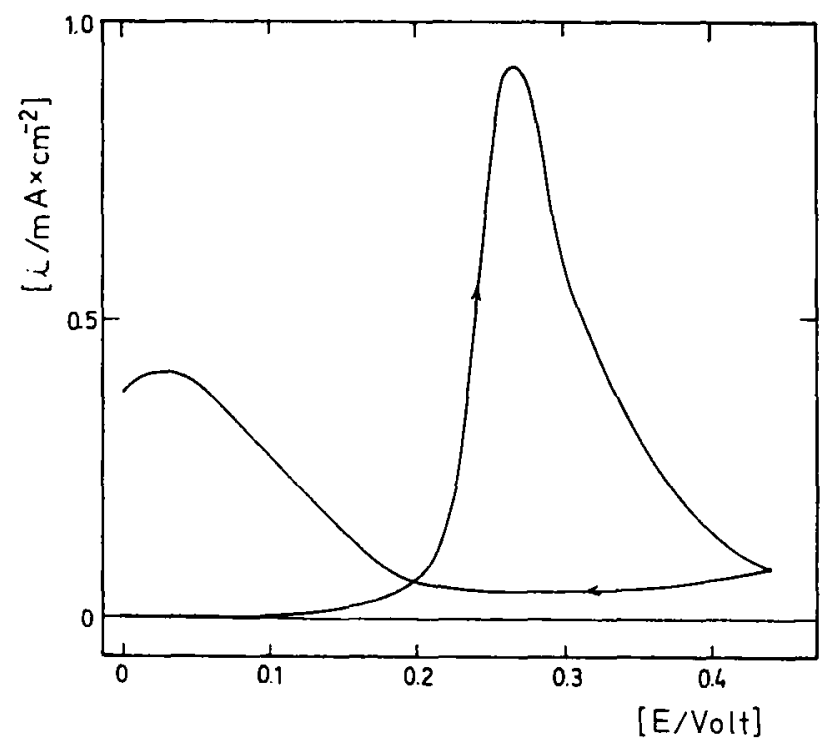

FIG. 4. Potentiodynamic anodic $E / I$ curve runs at $0.05 \mathrm{~V} / \mathrm{min}$. Solution $\mathrm{A}, 25^{\circ} \mathrm{C}$.

current peak at $c a .0 .010 \mathrm{~V}$ is shown after repetitive cycling. The charge playing part in the successive cycles decreases quite markedly. Within this range of potential each reverse cycle exhibits an anodic current which is larger than that recorded during the corresponding anodic scan.

With a fresh electropolished electrode and an anodic potential scan of $0.5 \mathrm{~V} / \mathrm{min}$ reaching $0.75 \mathrm{~V}$, peak I includes an appreciable anodic current contribution beyond $0.35 \mathrm{~V}$ and the following potential scans clearly indicate the onset of passivity (Fig. 5A). The electrode after recovering its rest potential reproduces the same characteristics, but peak $I$ is less defined because the current contribution at larger anodic potentials is relatively large (Fig. 5B).

It is interesting to note that the first portion of the returning $E / I$ profile obtained after the first anodic potential sweep (Fig. 6) exhibits a specular symmetry with the $E / I$ profile which would result during the current decay when no interruption of the potential at the anodic potential limit is made. The current decay should follow, under a simple controlled diffusion kinetics, an $I / t^{-\frac{1}{2}}$ linear relationship. The influence of the anodic potential limit up to $0.65 \mathrm{~V}$ on either the activation or passivation during successive potential cycles is also shown in Fig. 6.

The $E / I$ profiles recorded at different $v$ from -0.38 to $0.37 \mathrm{~V}(\Delta E=0.75 \mathrm{~V})$ (Figs. 7 and 8 ) exhibit a very good definition and genesis of the anodic current peak $\Pi$. These voltammograms start from $E_{r}$ towards $-0.38 \mathrm{~V}$ and backwards up to $0.37 \mathrm{~V}$, so that the electrode is cathodized before any anodic reaction occurs. Apart from the changes already described, an activation of the cathodic process is noticed during the successive potential cycling and, at the highest $v$ (Fig. 8), a clear cathodic current plateau is observed during the returning potential cycling in the potential range between -0.15 and $-0.25 \mathrm{~V}$. This cathodic limiting current, probably a very broad current peak covering a charge of the order of a monolayer, increases during the 


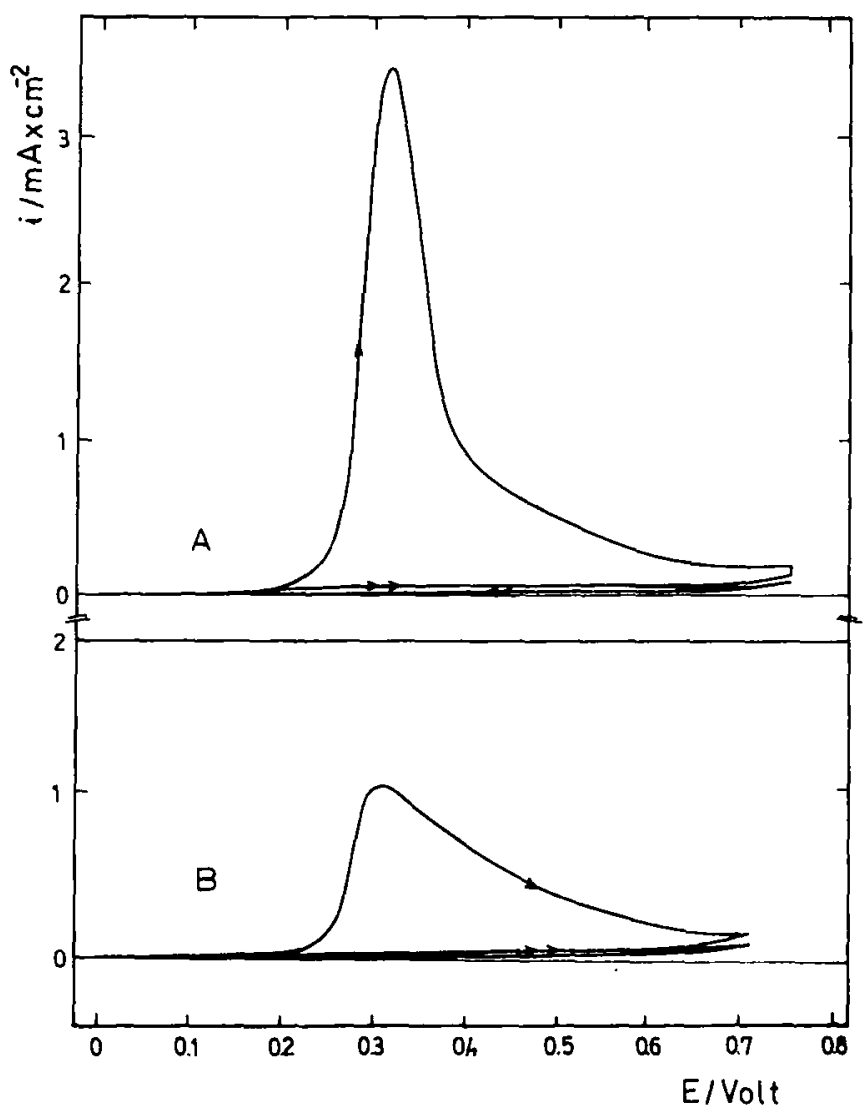

FIG. 5. $E / I$ displays recorded under the conditions inaicated in Fig. 2; (A) fresh electropolished electrode; (B) with the same electrode after its rest potential has been recovered.

potential cycling approaching a limiting charge. The height of the current peak II increases during cycling and correspondingly its potential becomes more negative. However, a limiting situation is attained after $n$ is ca. 25-30. The current peak potentials become more positive as $v$ increases and the height ratio of current peak I to current peak II increases when $v$ increases.

The $E / I$ displays at $50^{\circ} \mathrm{C}$ with a fresh electrode surface reproduce in a broad sense the characteristics described at lower temperatures. After the successive cycling at $v=6.0 \mathrm{~V} / \mathrm{min}$ (Fig. 9) the current peak I is practically no longer observed as such but as a kind of limiting current wave. On increasing $n$ the limiting current previously recorded at potentials in between the current peak potentials becomes a broad anodic current peak II, of which current peak I appears only as a shoulder at the right hand side of the $E / I$ display. The activation of the cathodic reaction due to cycling is more marked at $50^{\circ} \mathrm{C}$ than at $25^{\circ} \mathrm{C}$.

Another interesting result comes out with an electrode previously used and left in contact with the solution (Fig. 10). The experiment consists in keeping the electrode 


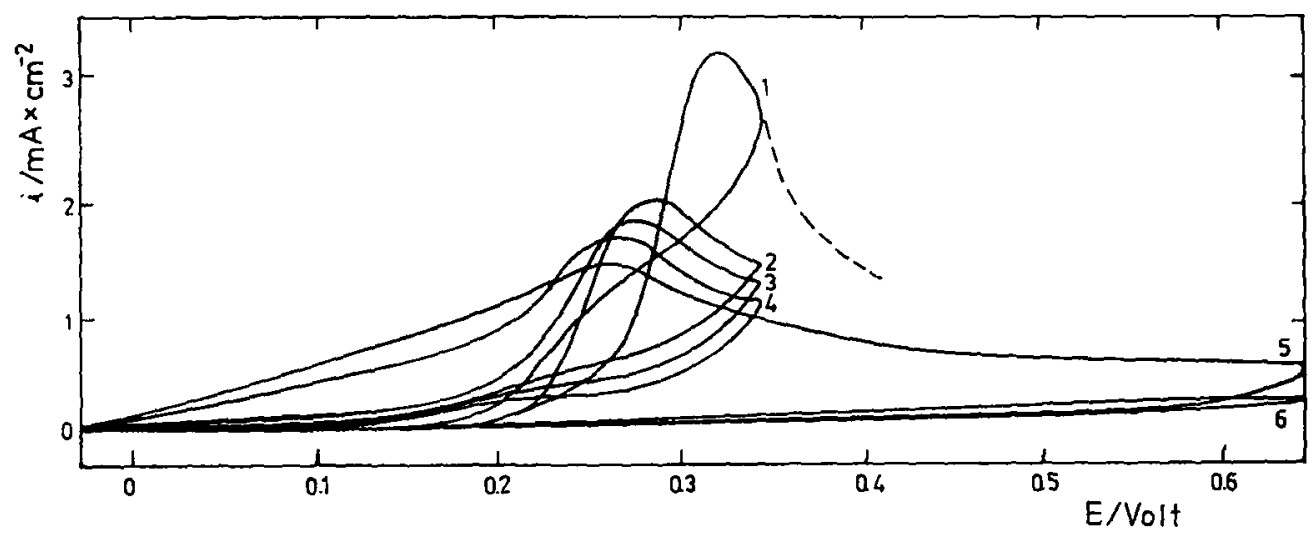

FIG. 6. Repetitive $E / I$ display at $0.5 \mathrm{~V} / \mathrm{min}$ extending the anodic potential limit during cycling. Solution $\mathrm{A}, 25^{\circ} \mathrm{C}$.

in solution at open circuit during 5 min with stirring, leaving it for $15 \mathrm{~min}$ to bring the solution to a standstill and finally to perturb the interface again with the cyclic triangular potential sweep at $0.5 \mathrm{~V} / \mathrm{min}$. Now the current peak II is no longer observed as a large current peak but becomes a shoulder of an intermediate broad current peak lying between 0.15 and $0.25 \mathrm{~V}$. These results are completely reproducible and are also obtained at higher potential scans, except for a shift of the peak potentials to the anodic potential side. Afterwards on cleaning the electrode, the behaviour formerly depicted (Fig. 9) can be reproduced again.

A set of experiments in which each cycle consists of a previous cathodization at $-0.36 \mathrm{~V}$ for different times before running the anodic sweep is shown in Fig. 11. Now in any cycle, the height of current peak I is always larger than that of current peak II, probably because the effect of cathodization yields a new metal surface for each run. The peak currents and potentials depend to some extent on the cathodization time.

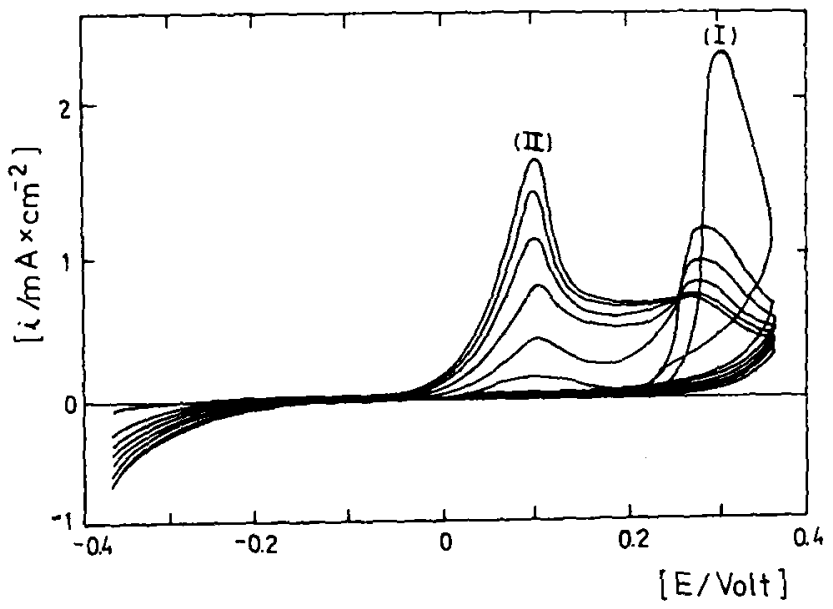

FIG. 7. E/I display obtained under the conditions indicated in Fig. 2 covering the potential region of the hydrogen solution. Solution $\mathrm{A}, 25^{\circ} \mathrm{C}$. 


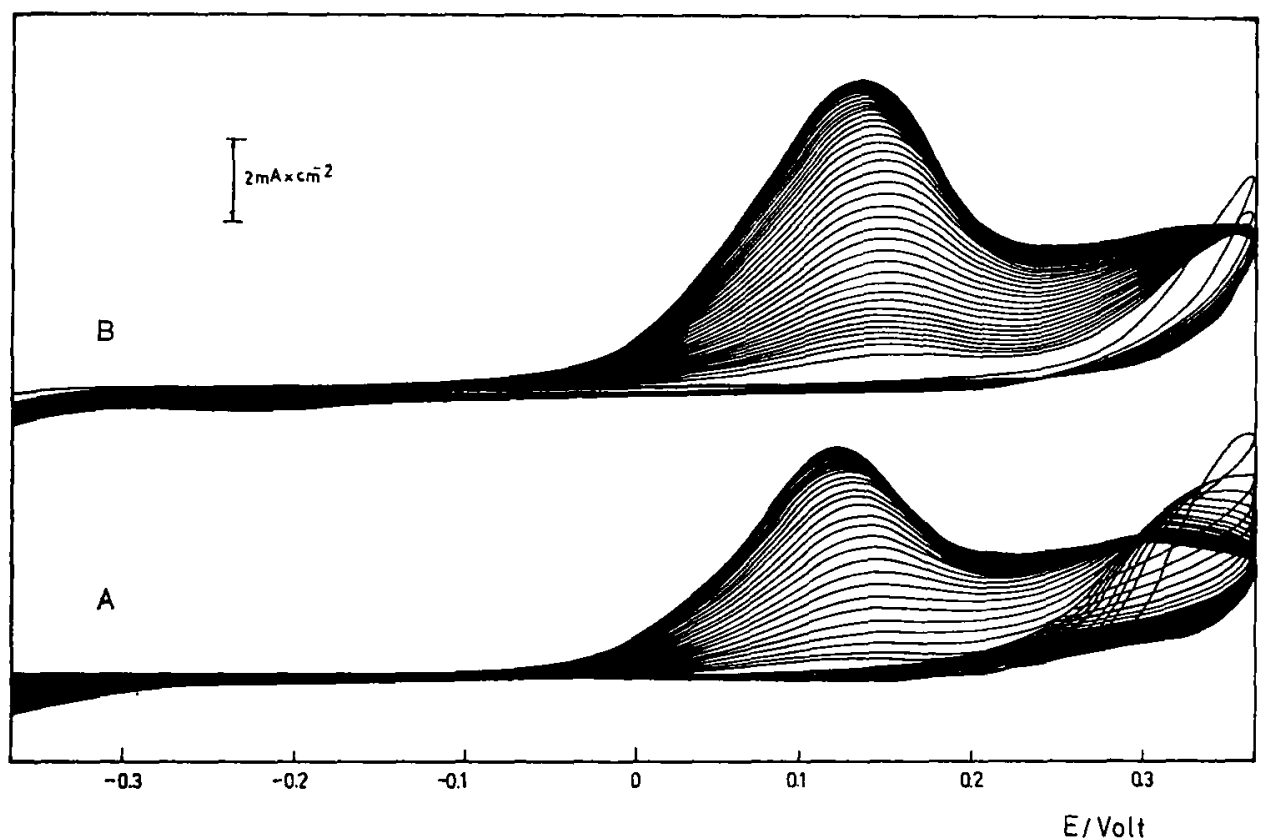

FIG. 8. Repetitive $E / I$ displays. Solution A at $8.0 \mathrm{~V} / \mathrm{min}$; Solution B at $15.0 \mathrm{~V} / \mathrm{min}$.

Although these results are rather too ambiguous to conclude from them any quantitative data, they exhibit the appearance of a small anodic current at $c a .-0.03 \mathrm{~V}$ during both the anodic and cathodic scans and the interception for $I=0$ occurs at $-0.11 \mathrm{~V}$.

The $E / I$ displays recorded with solution $\mathrm{B}$ at $50^{\circ} \mathrm{C}$ and $75^{\circ} \mathrm{C}$ depend as before on the perturbation conditions and on the previous history of the metal electrode. A series of voltammograms at $0.5 \mathrm{~V} / \mathrm{min}$ starting from $-0.36 \mathrm{~V}$ towards different potential limits, $E \lambda$, exhibits a peculiar behaviour of current peak $\Pi$ when $E \lambda \simeq 0.25 \mathrm{~V}$

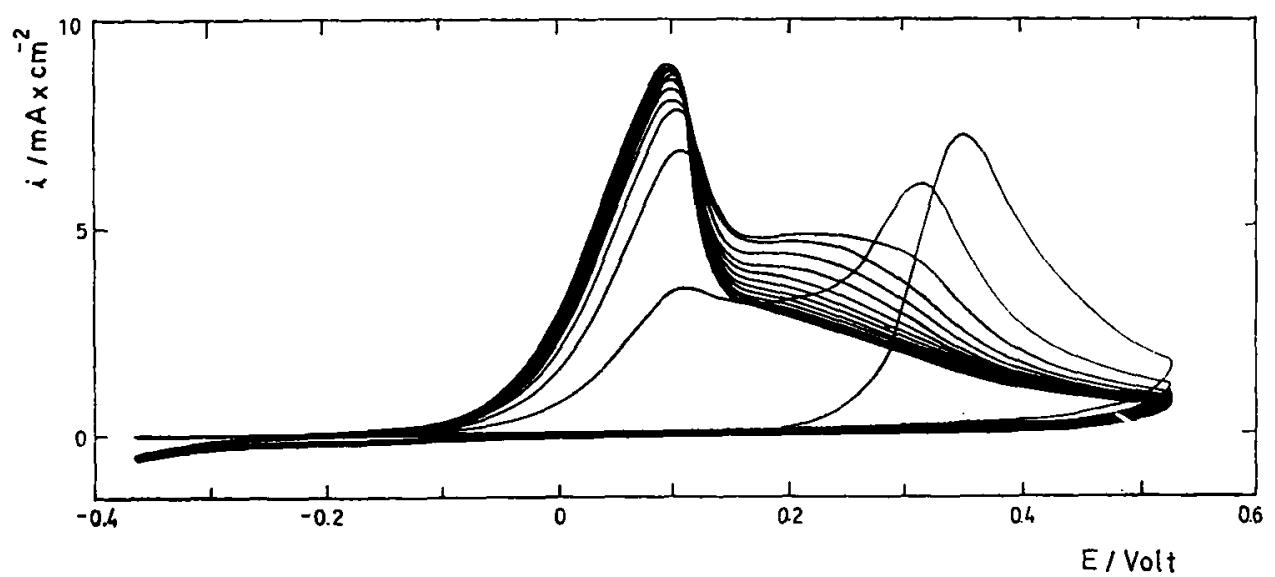

FIG. 9. Voltammogram recorded at $6.0 \mathrm{~V} / \mathrm{min}$. Solution $\mathrm{A}, 50^{\circ} \mathrm{C}$. 


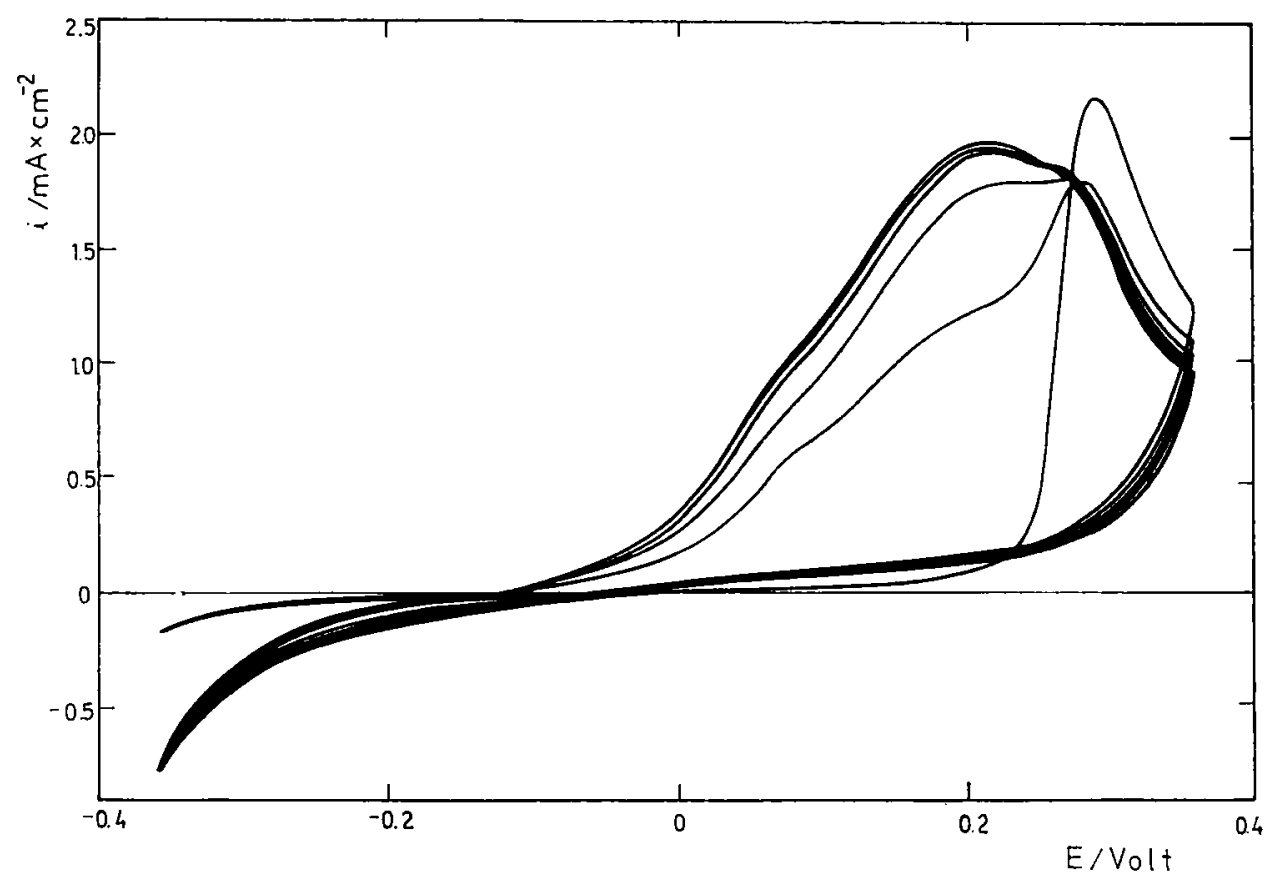

FIG. 10. E/I display obtained at $0.5 \mathrm{~V} / \mathrm{min}$ with an electrode previously used and treated as described in the text. Solution $\mathrm{A}, 50^{\circ} \mathrm{C}$.

(Fig. 12). Thus, current peak II magnifies as the anodic potential limit becomes smaller.

The following relationships are derived from the potentiodynamic runs obtained at different temperatures with both solutions. The heights of current peaks I and II, the latter referred at $n \rightarrow \infty$, both increase with v, although at present no clear linear relationships either $I_{p} / v^{1 / 2}$ or $I_{p} / \log v$ can be well established. The potentials of both current peaks apparently fit linear $E_{p}$ vs $\ln v$ relationships, their slopes being close to the $2 R T / 3 F$ ratio. The pseudo-limiting current recorded during the first anodic potential scan in the potential range preceding current peak I increases linearly with $v^{1 / 2}$ and the same type of relationship is apparently fulfilled for the limiting current attained after the $n$th cycle in the potential region comprised between the current peak potentials.

The ascending branch of the anodic current peak I of the first scan approaches two limiting Tafel lines. At low potentials the limiting slope can be taken as $2 R T / F$ while at a high potential range, after the pseudo-limiting current region, the slope covers a wide range of values from $c a . R T / 2 F$ to $R T / F$. The higher $v$ and the lower $T$, the larger the Tafel slope. The ascending branch of the anodic current peak II at the $n$th cycle fits a Tafel line within the potential range from -0.10 to $0.05 \mathrm{~V}$, with a slope of $0.080-0.090 \mathrm{~V} /$ decade in the temperature range investigated, which is independent of $v$ within $4 \leq v \leq 15 \mathrm{~V} / \mathrm{min}$.

The potential for $I=0$ depends on the direction of the potential sweep as well as the values of $v$ and $E \lambda$. The activation of the returning halfcycle referred to current 


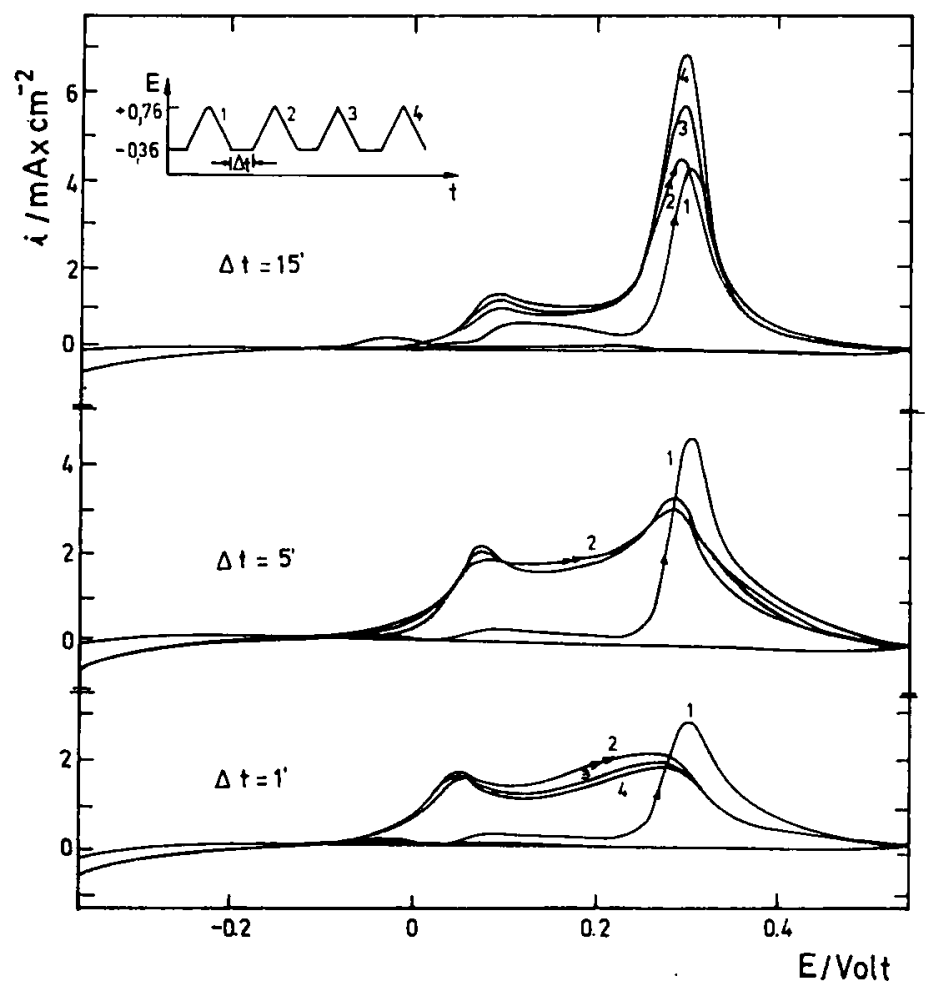

FIG. 11. E/I displays recorded after a previous cathodization at $-0.36 \mathrm{~V}$ for different times before each run. Solution $\mathrm{A}, 50^{\circ} \mathrm{C}$.

peak II increases when $v$ decreases, when the temperature increases, and when $E \lambda$ decreases. The activation effect is always greater when a used electrode is employed and also increases when the acidity increases.

Potentiodynamic runs with stirring and asymmetric triangular potential perturbations

The effect of stirring ( $w$ rotation speed of the r.d.e.) in the potentiodynamic runs is more remarkable at low $v$. The changes involved at $w \neq 0$ are always larger than those with still solution. For solution $A$ an outstanding stirring effect is noticed in the potential range $0.25-0.45 \mathrm{~V}$ where current peak $\mathrm{I}$ is recorded (Fig. 13). The returning $E / I$ contours show $I=0$ at a potential close to $E_{r}$ for $t \rightarrow 0$, but for the anodic scan the potential at which $I=0$ is $c a .0 .1 \mathrm{~V}$ more cathodic than $E_{r}$.

The influence of the scan rate just described is in correspondence with the characteristics of the $E / I$ displays obtained under a triangular potential perturbation with $v_{a} \neq v_{c}$ (Fig. 14). Thus, during the successive potential cycling, current peak I magnifies both when $v_{a}>v_{c}$ and when $w \neq 0$, while the reverse occurs with current peak II. Moreover, current peak II becomes clearly defined when $v_{c}<v_{a}$.

The analysis of the voltammograms recorded with the $\mathrm{Ni}$ r.d.e. shows that the Tafel plots for the positive branches of current peaks agree with the values already described and the same occurs with the $E_{p} / \log v$ relationships. Both current peak poten- 


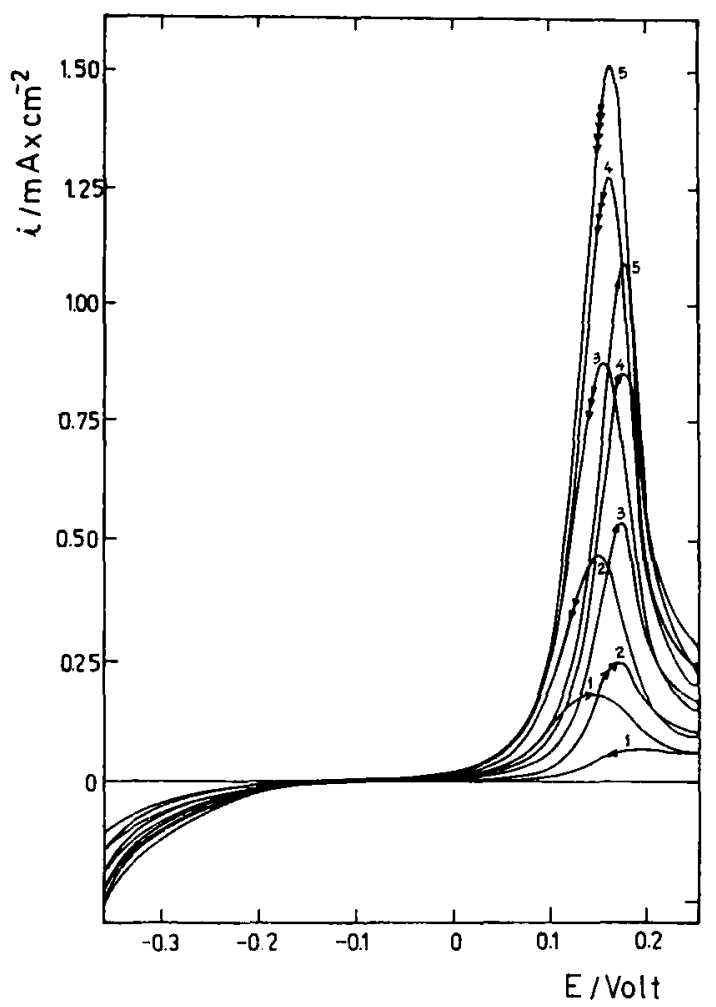

Fig. 12. Voltammogram recorded at $0.5 \mathrm{~V} / \mathrm{min}$. $E \lambda=0.25 \mathrm{~V}$. Solution $\mathrm{B}, 50^{\circ} \mathrm{C}$.

tials are independent of $w$. The limiting current attained after the $n$th cycle in the potential range between the current peak potentials increases linearly with $v^{\frac{k}{2}}$ at constant $w$ (Fig. 15) and also linearly with $w^{\frac{1}{2}}$ at constant $v$ (Fig. 16). The height of current peak $\Pi$ decreases when $w$ increases (Fig. 17), while the current peak II potential increases with $\log v$, the slope being close to the $2.303(2 R T / 3 F)$ ratio (Fig. 18). No $I_{p} / v^{\sharp}$ nor $I_{p} / \log v$ simple relationship is found for the dependence of the height of current peak II on $v$ after the $n$th cycle (Fig. 19).

\section{Potentiostatic steps}

The $I /$ time response of the $\mathrm{Ni} /$ solution $\mathrm{B}$ interface starting with freshly polished electrodes after different potentiostatics steps, $E$, is relatively complex (Fig. 20). When $E \leq 0.245 \mathrm{~V}$, the $1 /$ time record shows a clear current minimum, $I_{m}$ at $t_{m i n}$ and a linear $E / \log t_{\min }$ relationship is apparently obeyed. The charge involved up to $t_{\min }$ is on the average $c a .0 .9 \mathrm{mC} / \mathrm{cm}^{2}$ and this magnitude is apparently independent of $E$. The current minimum is no longer observed when $E>0.245 \mathrm{~V}$. Furthermore for $0.220 \leq E \leq 0.255 \mathrm{~V}$, a well defined maximum current, $I_{M}$, is observed, at $t_{\max }$. The charge involved up to $I_{M}$ is $c a .30 \mathrm{mC} / \mathrm{cm}^{2}$. As $t \rightarrow \infty$, the current asymptotically decreases to $20 \mu \mathrm{A} / \mathrm{cm}^{2}$ thereabouts as it corresponds to a passivity current. 


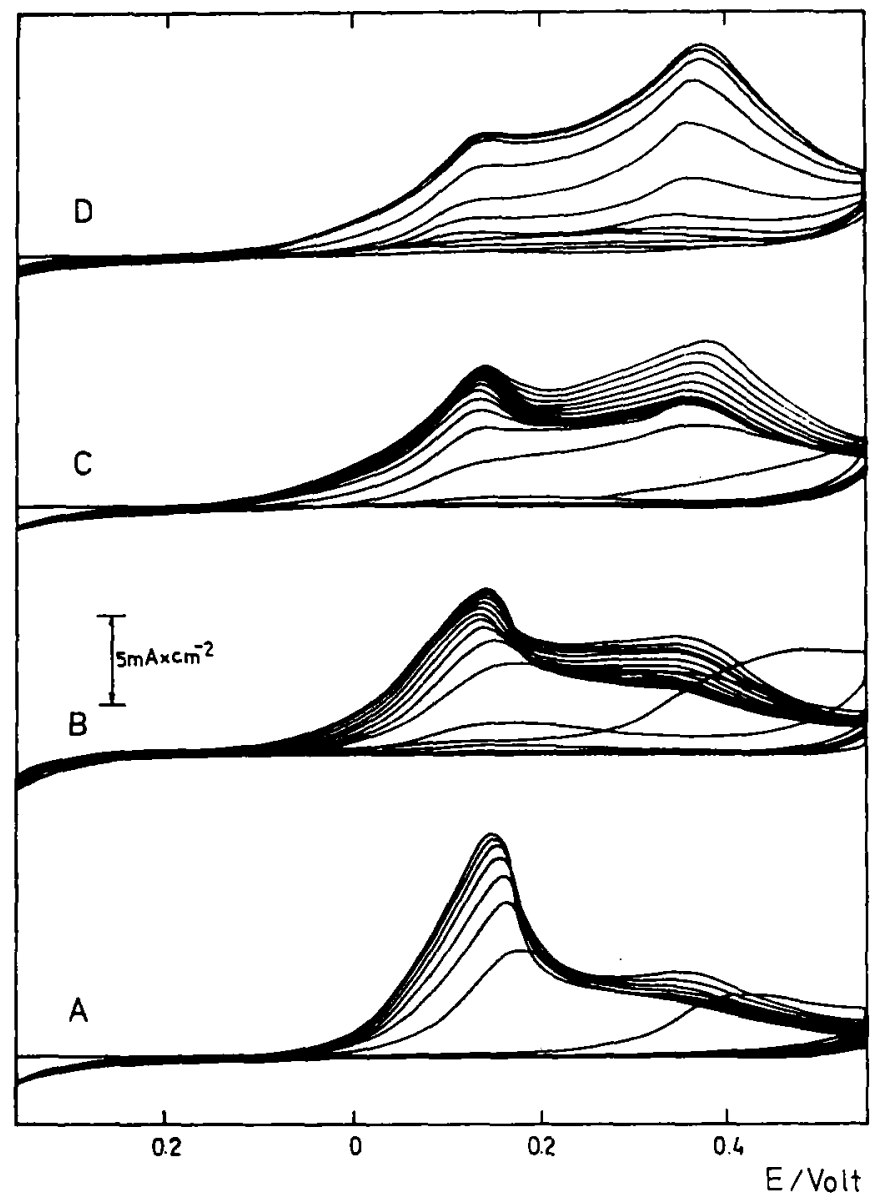

FIG. 13. Repetitive triangular potential sweeps obtained at $5.0 \mathrm{~V} / \mathrm{min}$ with a Ni r.d.e.; (A) $w=0$; (B) $428 \mathrm{rpm}$; (C) $830 \mathrm{rpm}$; (D) $1600 \mathrm{rpm}$. Solution A, $50^{\circ} \mathrm{C}$.

\section{Potentiostatic E/I relationships}

The corresponding "stationary" $E / \log I$ plots obtained under potentiostatic conditions depend quite markedly on the time spent between the current readings. The current values read after 3 min polarization starting from $E_{r}$ approach a single straightline with a slope close to the $2.303 R T / F$ ratio, as usually reported by different authors, as the value of the stationary Tafel slope. Different straight lines can be drawn from the potentiostatic stationary $E / \log I$ plots, depending on the chosen potential range, but the various changes occurring at the metal/electrolyte interface during potentiodynamic polarization support the idea that a Tafel slope derived from $E / \log I$ plots by imposing a particular potential during an arbitrary time probably becomes of a secondary importance as a kinetic parameter for a mechanistic diagnosis. 


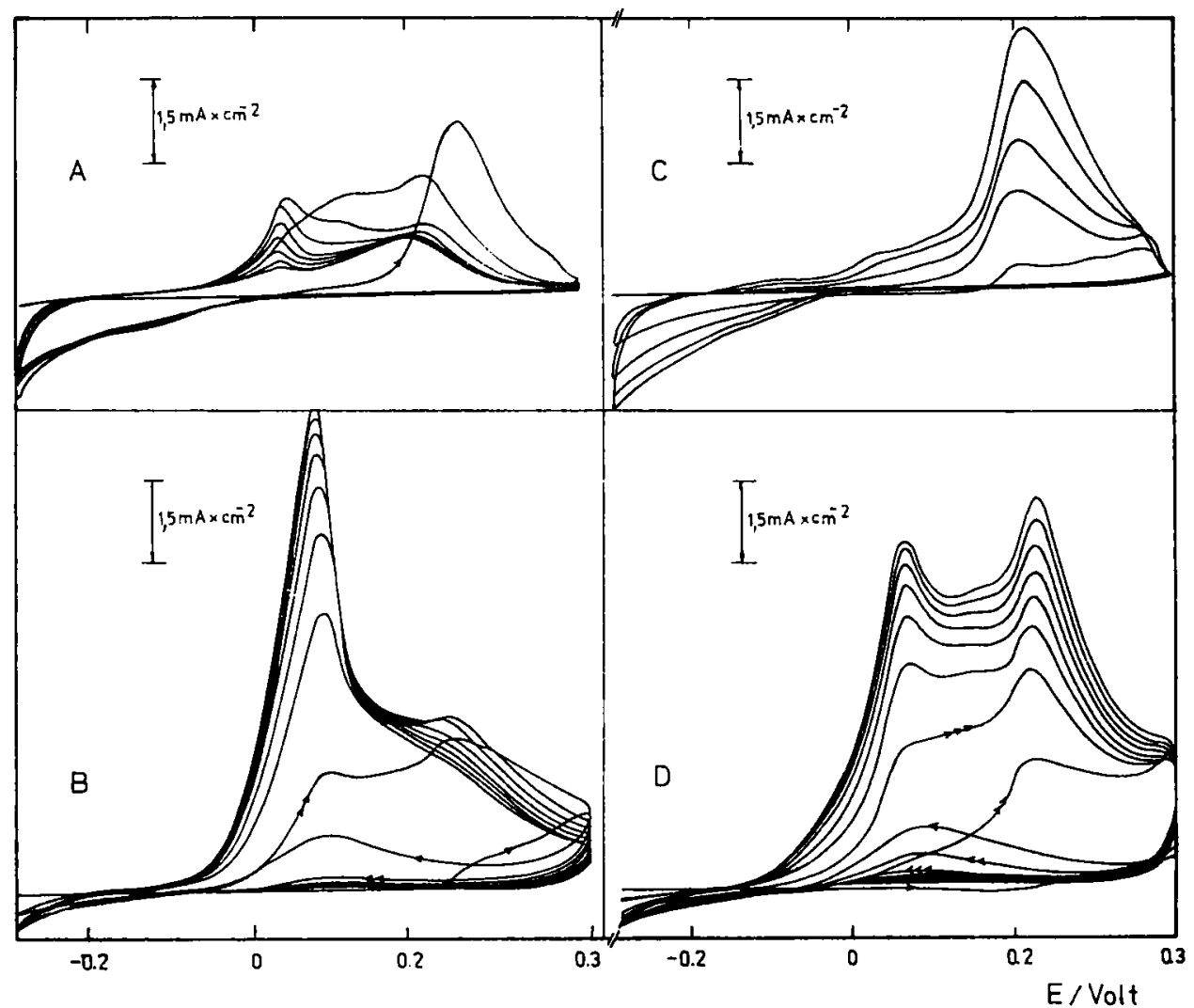

FIG. 14. $E / I$ displays recorded with asymmetric triangular potential perturbations. Solution B, $50^{\circ} \mathrm{C}$; (A) $v_{a}=0.5 \mathrm{~V} / \mathrm{min}, v_{e}=5.0 \mathrm{~V} / \mathrm{min}, w=0$; (B) $v_{\mathrm{s}}=5.0 \mathrm{~V} / \mathrm{min}$, $v_{c}=0.5 \mathrm{~V} / \mathrm{min}, w=0 ;$ (C) $v_{a}=0.5 \mathrm{~V} / \mathrm{min}, v_{a}=5.0 \mathrm{~V} / \mathrm{min}, 1600 \mathrm{rpm}$; (D) $v_{a}=$ $5.0 \mathrm{~V} / \mathrm{min}, v_{e}=0.5 \mathrm{~V} / \mathrm{min}, 1600 \mathrm{rpm}$.

\section{DISCUSSION}

Anion adsorption, active dissolution and passivation

The kinetic studies made on the corrosion and passivity of $\mathrm{Ni}$ in acid aqueous media containing only either $\mathrm{SO}_{4}{ }^{2-}$ or $\mathrm{ClO}_{4}{ }^{-}$anions reveal a similar potentiodynamic behaviour. The electrochemical process in $\mathrm{Cl}^{-}$ion-containing solutions is appreciably different since the aggressive characteristics of $\mathrm{Cl}^{-}$ion produce a net anodic dissolution of the metal. From all these results it seems quite reasonable to assume that the electrochemical oxidation of $\mathrm{Ni}$, related either to corrosion or passivity, involves at least two competing processes, which can be expressed as follows:

$$
x_{1} M+y_{1} X^{-} \stackrel{K_{1, g}}{\rightleftharpoons} M_{x 1}\left(X^{-}\right)_{y 1} \stackrel{k_{1, g}}{\rightarrow} P_{1}+P_{2}+\ldots+P_{n},
$$

and

$$
x_{2} M+y_{2} \mathrm{H}_{2} \mathrm{O} \stackrel{K_{2}}{\rightleftharpoons} M_{x 2}\left(\mathrm{H}_{2} \mathrm{O}\right)_{y 2} \stackrel{k_{2,8}}{\rightarrow} P_{1}^{\prime}+P_{2}^{\prime}+\ldots+P_{n}^{\prime}
$$




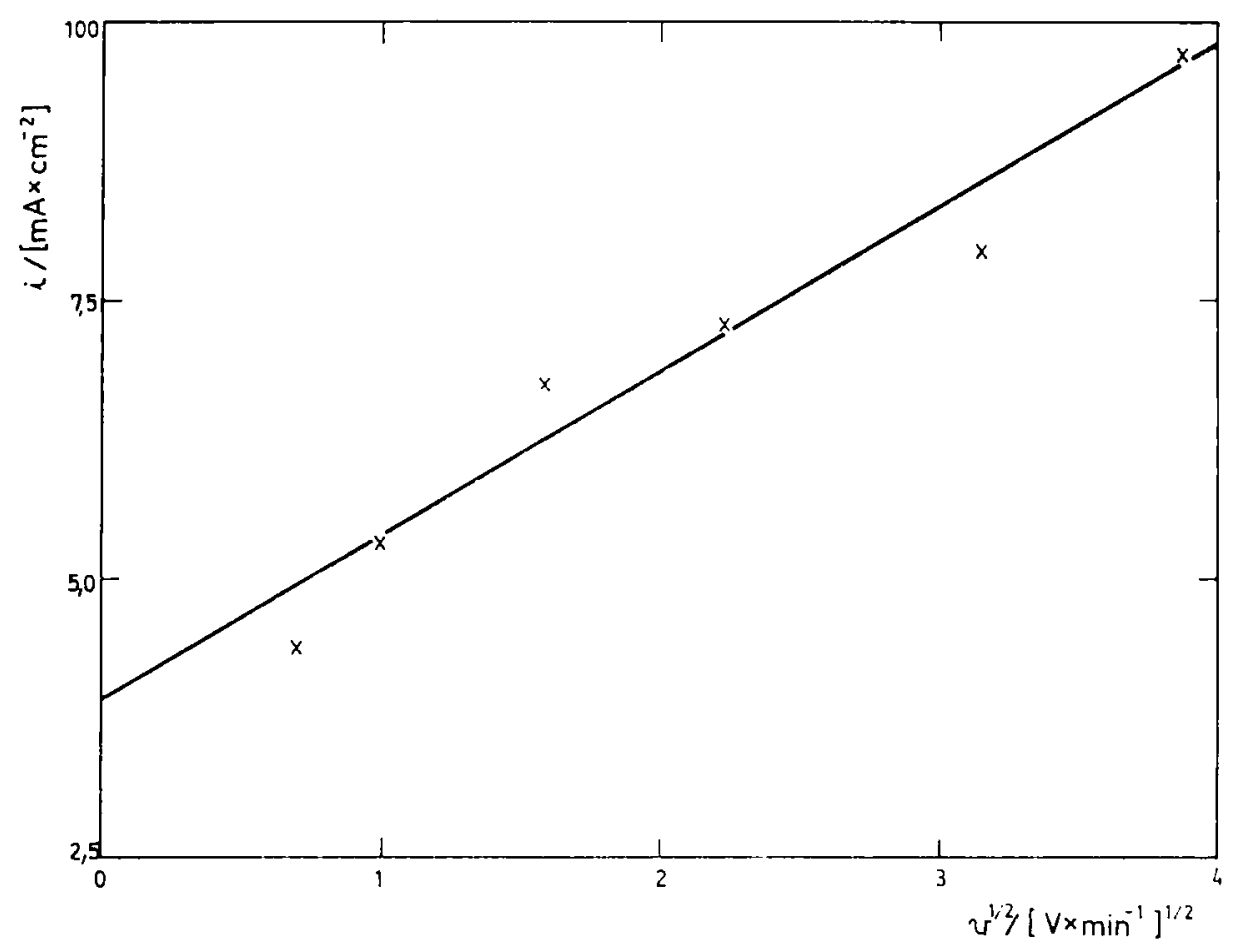

Fig. 15. Dependence of the limiting current on the potential sweep rate in the potential range between both anodic current peaks. Solution $\mathrm{B}, 50^{\circ} \mathrm{C}, w=830 \mathrm{rpm}$.

Reaction (1) corresponds to the initial anion $\left(X^{-}\right)$specific adsorption on the metal $(M)$ followed by a series of successive electrochemical and chemical steps yielding the final products $P_{i}$, such as $M^{z+}, M X_{n}{ }^{\left({ }^{n-z}\right)^{-}}, M X_{p}$, etc. Reaction (2) implies solvent adsorption, which occurs, as before, through a series of consecutive steps and yields another set of reaction products $P_{i}{ }^{\prime}$, namely $M\left(\mathrm{H}_{2} \mathrm{O}\right)_{q}{ }_{q}{ }^{2+}, M(\mathrm{OH})_{z}, M \mathrm{O}_{z}$, etc. $K_{1}$ and $K_{2}$ are the equilibrium constants of the corresponding adsorption processes, whose magnitudes depend on $\left(\Delta G^{0}{ }_{\text {ads }}\right)_{1}$ and $\left(\Delta G^{0}{ }_{a d s}\right)_{2}$, the changes of the standard free energy of adsorption for the anion and for the solvent respectively. $k_{1, g}$ and $k_{2, g}$ are the apparent rate constants of processes (1) and (2) respectively. $x$ and $y$ are the stoichiometric coefficients related to the total number of available sites on the metal surface. Then, $x_{1}+x_{2}=1$ and $y_{1}+y_{2}=1$ since it is assumed that no bare metal sites actually exist on the electrode dipped into the electrolytic solution. Consequently, $0 \leq x_{1} \leq 1,0 \leq x_{2} \leq 1,0 \leq y_{1} \leq 1$ and $0 \leq y_{2} \leq 1$, and on the assumption that each metal site corresponds to a single adsorbed species, when a monolayer of adsorbed species is attained either $x_{1} \rightarrow y_{1}$ or $x_{2} \rightarrow y_{2}$. Therefore, the relative contribution of processes (1) and (2) depends on the $\left(\Delta G_{\text {ads }}^{0}\right)_{1} /\left(\Delta G^{0}{ }_{\text {ads }}\right)_{2}$ ratio.

Although not quantitatively well established yet, previous studies of various metal/acid aqueous solution interfaces indicate that the adsorbability of the $\mathrm{Cl}^{-}$ion is larger than that of the $\mathrm{ClO}_{4}{ }^{-}$and $\mathrm{SO}_{4}{ }^{2-}$ ions. Furthermore, for the former it has been advanced the possible formation of surface complex species caused by the 


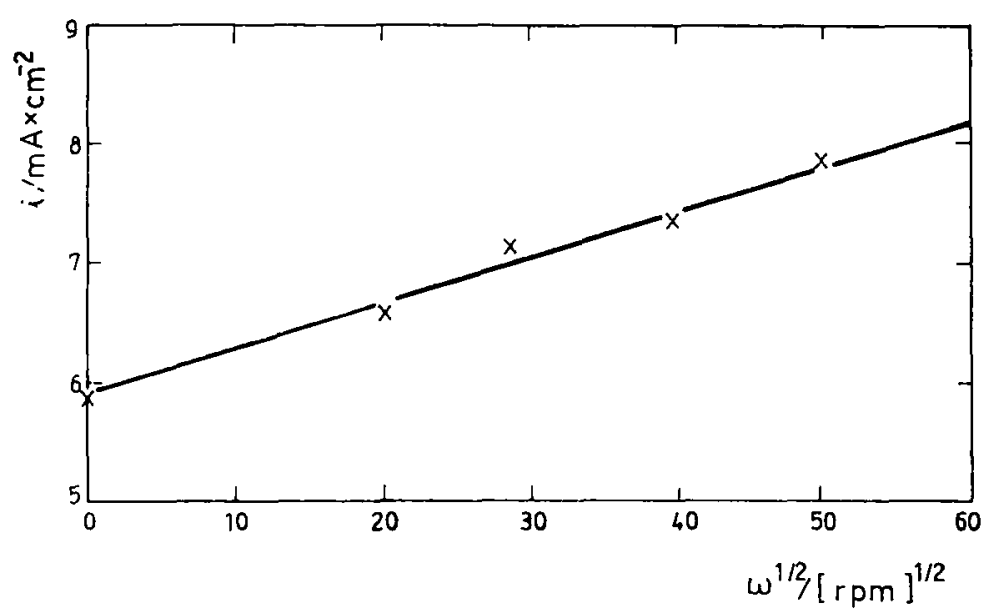

FIG. 16. Dependence of the limiting current on the speed of the r.d.e. in the potential range between both anodic current peaks. Solution $\mathrm{B}, 50^{\circ} \mathrm{C} ; v=5.0 \mathrm{~V} / \mathrm{min}$.

overlapping of the halide and metal orbitals. ${ }^{20} \mathrm{~A}$ consequence of this is the active anodic dissolution of $\mathrm{Ni}$ in the $\mathrm{Cl}^{-}$ion-containing solution and the relatively smaller contribution of any oxygen containing film on the metal passivation. In this case, the onset of passivation may be due to precipitation of an insoluble salt at the metal/ electrolyte interface. Otherwise, the adsorbabilities of $\mathrm{ClO}_{4}{ }^{-}$and $\mathrm{SO}_{4}{ }^{2-}$ ions, even comparatively smaller than that of $\mathrm{Cl}^{-}$ions, are likely to be of the same order of magnitude. Therefore, under these circumstances the major metal-anion interactions are of electrostatic origin, their corresponding $\left(\Delta G^{0}{ }_{\text {ads }}\right)_{1}$ becoming relatively small as compared to that of $\mathrm{Cl}^{-}$ion. Consequently, the contribution of reaction (1) decreases while that of reaction (2) increases in passing from the $\mathrm{Cl}^{-}$ion to either $\mathrm{SO}_{4}{ }^{2-}$ or $\mathrm{ClO}_{4}{ }^{-}$ion containing solutions. The changes of the instantaneous $\mathrm{pH}$ values at the vicinity of the electrode will depend on the magnitude of the relative contributions of reactions (1) and (2) and, consequently, for the case of a transient perturbation, on the rate of perturbation of the electrical parameters at the interface. This simple approach permits a reasonable interpretation of the influence of the anions on the kinetics of Ni electrodissolution and passivation, as discussed further on.

\section{The immersion potential and the rest potential}

The potential acquired by the $\mathrm{Ni}$ electrode immediately in contact with the solution is more negative than $E_{r}$, the potential approached after several hours. The former potential, $\left(E_{r}\right)_{t=0}$, lies within the potential range of the $\mathrm{H}_{2} / \mathrm{H}^{+}$electrode and the $\mathrm{Ni} / \mathrm{Ni}^{2+}$ electrode and it corresponds to the corrosion potential of the $\mathrm{Ni}$ in the acid electrolyte. On the other hand, $E_{r}$ is more positive than the reversible potential of any of those electrodes and its value can be immediately compared to the potentials, at $25^{\circ} \mathrm{C}$, of any of the following equilibria ${ }^{21,22}$ :

$$
\mathrm{Ni}+\mathrm{H}_{2} \mathrm{O}=\mathrm{NiO}+2 \mathrm{H}^{+}+2 e^{-} \quad E^{0}=0.110 \mathrm{~V}
$$




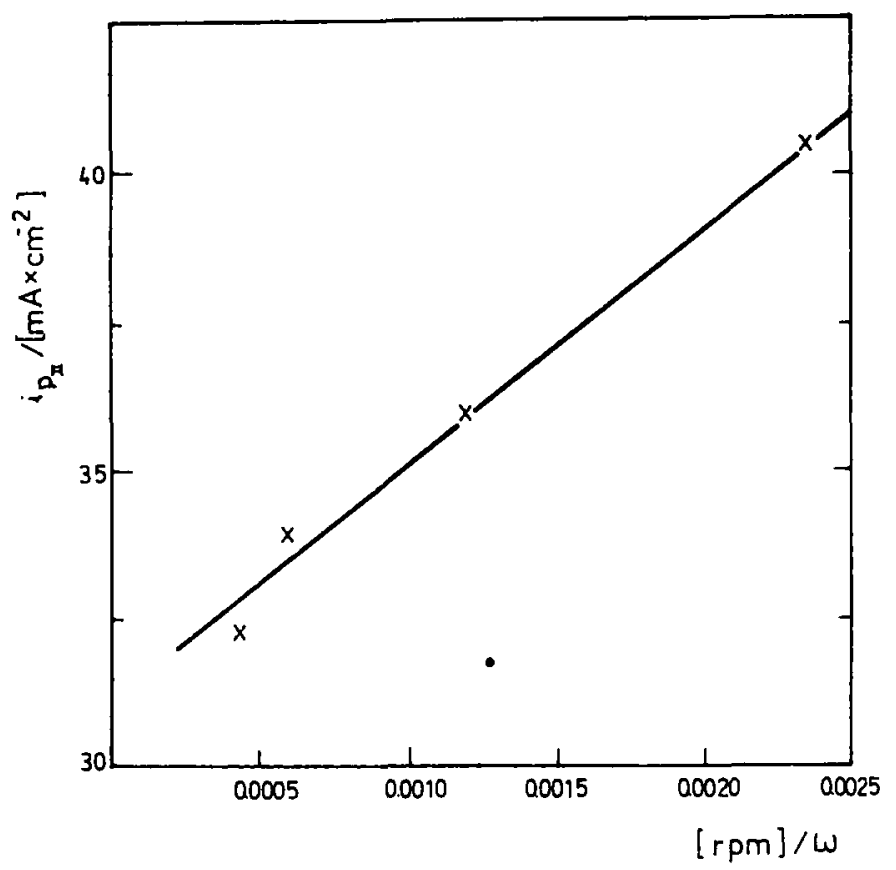

FiG. 17. Dependence of current peak II potential on the speed of the r.d.e. Solution $\mathbf{B}$, $50^{\circ} \mathrm{C}$.

$$
\begin{array}{ll}
\mathrm{Ni}+2 \mathrm{H}_{2} \mathrm{O}=\mathrm{Ni}(\mathrm{OH})_{2}+2 \mathrm{H}^{+}+2 e^{-} & E^{0}=0.116 \mathrm{~V} \\
\mathrm{Ni}+2 \mathrm{H}_{2} \mathrm{O}=\mathrm{NiO} . \mathrm{H}_{2} \mathrm{O}+2 \mathrm{H}^{+}+2 e^{-} & E^{0}=0.117 \mathrm{~V} .
\end{array}
$$

More than a decade ago reactions (3)-(5) were considered as determining the $E_{r}$ of $\mathrm{Ni}$ in acid solutions. ${ }^{23}$ The corresponding $\Delta E^{0} / \Delta \mathrm{pH}$ coefficient is $-2.303 R T / F$, a value which is twice the one found for $\Delta E_{r} / \Delta \mathrm{pH}$. Apart from this drawback, however, another difficulty arises in assigning $E_{r}$ to an equilibrium which under no circumstances can be experimentally evidenced.

It seems more reasonable to suggest that the rest potential is related to some irreversible process occurring on $\mathrm{Ni}$. This must be associated to an initial chemical decomposition of water on the metal and a subsequent electron transfer process such as:

$$
\begin{gathered}
2 \mathrm{Ni}+\mathrm{H}_{2} \mathrm{O}=[\mathrm{Ni}(\mathrm{H})+\mathrm{Ni}(\mathrm{OH})] \\
{[\mathrm{Ni}(\mathrm{H})+\mathrm{Ni}(\mathrm{OH})]=\mathrm{Ni}+\left(\mathrm{NiOH}^{+}\right)+\mathrm{H}^{+}+2 e^{-},}
\end{gathered}
$$

or as an overall electrochemical reaction:

$$
\mathrm{Ni}+\mathrm{H}_{2} \mathrm{O}=\left(\mathrm{NiOH}^{+}\right)+\mathrm{H}^{+}+2 e^{-} .
$$

The occurrence of reaction (6a) is widely sustained by water adsorption studies 


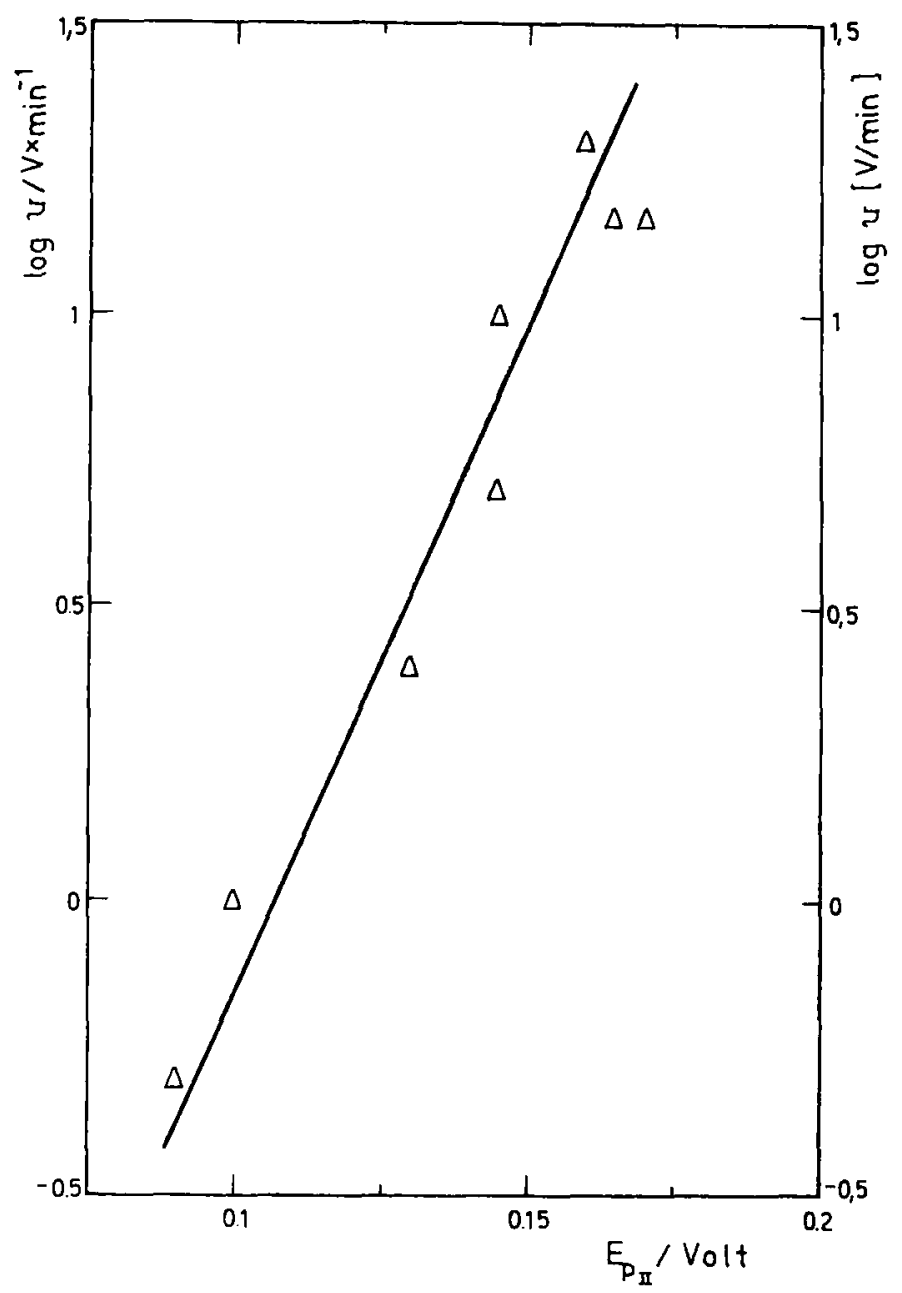

FIG. 18. Dependence of the current peak II potential on the potential sweep rate. Solution $\mathrm{A}, 50^{\circ} \mathrm{C}, w=830 \mathrm{rpm}$.

on $\mathrm{Ni}^{24}$ and the existence of the $\left(\mathrm{NiOH}^{+}\right)$species is largely justified for an electrode surface whose potential is by far more positive than the potential of zero charge of Ni $\left(E_{z}=-0.30 \mathrm{~V}\right){ }^{25}$ The $\Delta E / \Delta \mathrm{pH}$ coefficient obtained from (6) coincides now with the experimental value $(\Delta E / \Delta \mathrm{pH}=-2.303 R T / 2 F)$. Therefore, the time dependence of the $\mathrm{Ni}$ electrode potential to attain the $E_{r}$ value is interpreted as an accumulation of the hydroxo-positively-charged species on the electrode surface.

\section{Kinetic interpretation}

Two starting premises are advanced to understand the kinetic characteristics of the $\mathrm{Ni} /$ solution interface. First, in the presence of $\mathrm{SO}_{4}{ }^{2}$ - ions reaction (2) represents the major contribution to the electrochemical process. Secondly, it is assumed that within the potential range corresponding to the active dissolution and to the 


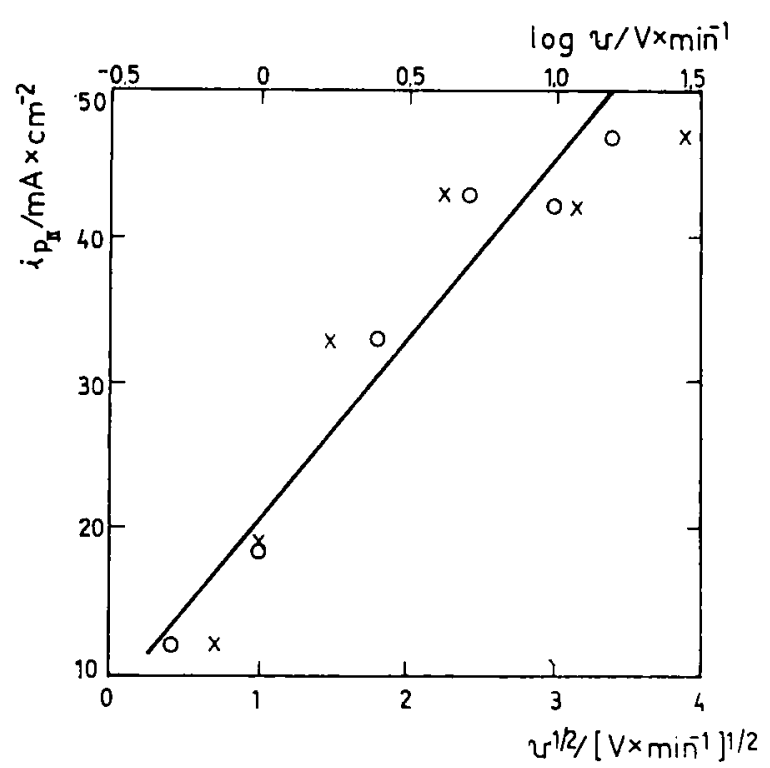

FIG. 19. Dependence of the height of current peak II on the potential sweep rate.

(X) $I_{p}$ vs $v^{1 / 2}$; (O) $I_{p}$ vs $\log v$. Solution $\mathrm{A}, 50^{\circ} \mathrm{C}, w=830 \mathrm{rpm}$.

onset of passivity, the Ni side of the electrochemical interface is always positively charged with respect to the solution side. This implies that any intermediate species, either neutral or ionic, remaining on the metal surface should be interacting with the electrode charge. Under these circumstances, the result is the electrode surface behaving as if it is partially covered by a species of the ionic type.

Under an anodic polarization the initial stages related to the $\mathrm{Ni}$ dissolution can formally be put as follows:

$$
\begin{gathered}
\mathrm{Ni}+\mathrm{H}_{2} \mathrm{O}=(\mathrm{NiOH})+\mathrm{H}^{+}+e^{-} \\
(\mathrm{NiOH})=\left(\mathrm{NiOH}^{+}\right)+e^{-} .
\end{gathered}
$$

The $(\mathrm{NiOH})^{+}$species can undergo any of the following reactions.

$$
\begin{gathered}
\left(\mathrm{NiOH}^{+}\right)+\mathrm{H}^{+}=\mathrm{Ni}^{2+}+\mathrm{H}_{2} \mathrm{O} \\
\left(\mathrm{NiOH}^{+}\right)+\mathrm{H}_{2} \mathrm{O}=\mathrm{Ni}(\mathrm{OH})_{2}+\mathrm{H}^{+} .
\end{gathered}
$$

Step (7c) yields a dissolved species and consumes $\mathrm{H}^{+}$ions at the interface, while step (7d) yields a sparingly soluble species and decreases the local $\mathrm{pH}$ value. Steps (7a)-(7c) correspond to the mechanism of Bockris et al. for the electro-dissolution of the iron family metals in acid aqueous solutions $\mathrm{s}^{26,27}$ when step (7b) is the r.d.s. $\mathrm{A} \mathrm{pH}$ independent process is implied when step (7d) becomes the r.d.s. The $\mathrm{Ni}(\mathrm{OH})_{2}$ formation at the interface indicates the possible contribution of the following reactions: 


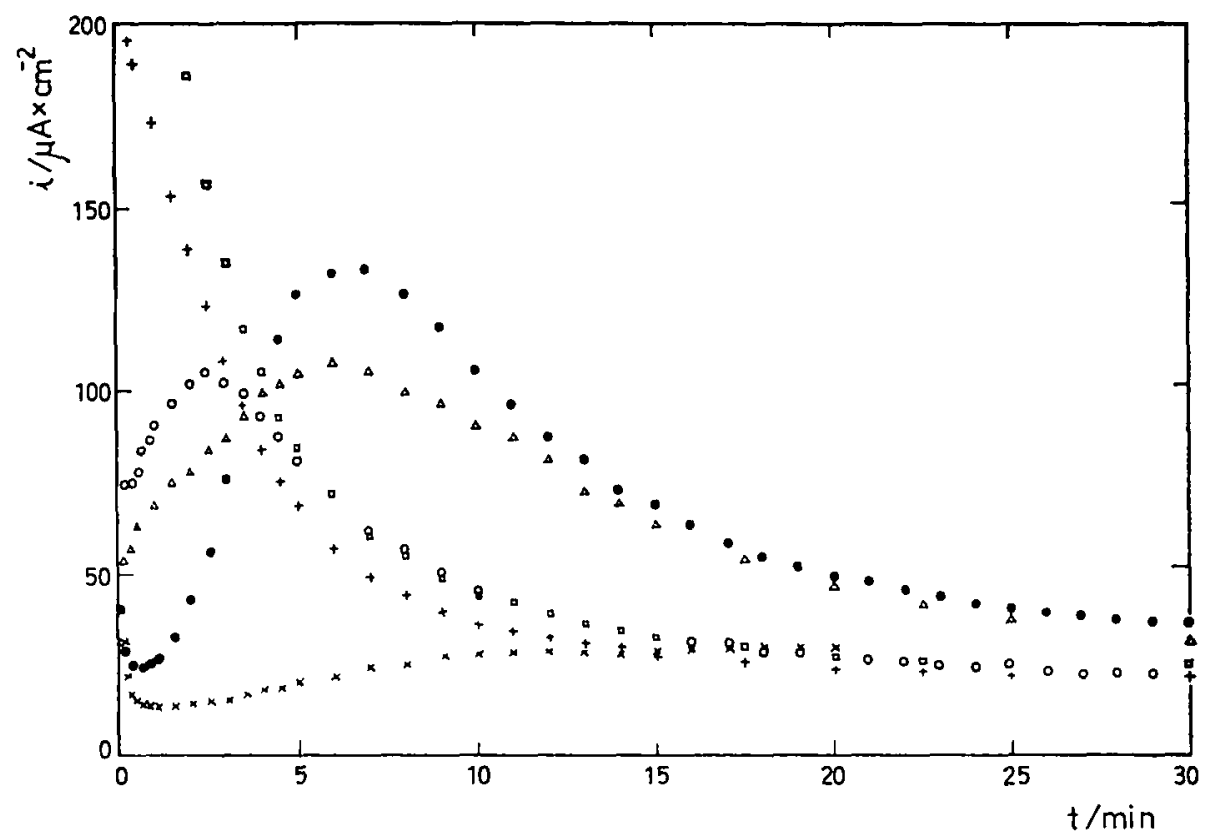

FIG. 20. Current/time records obtained after application of potentiostatic steps starting at the rest potential; $(\times) E=0.200 \mathrm{~V} ;(\bullet) E=0.220 \mathrm{~V} ;(\triangle) E=0.235 \mathrm{~V} ;(0) E=$ $0.245 \mathrm{~V} ;(+) E=0.255 \mathrm{~V}$; ( $\square) E=0.285 \mathrm{~V}$. Solution $A, 25^{\circ} \mathrm{C}$.

$$
\begin{gathered}
\mathrm{Ni}\left(\mathrm{OH}_{2}=\mathrm{NiO}+\mathrm{H}_{2} \mathrm{O}\right. \\
\mathrm{Ni}(\mathrm{OH})_{2}+\left(\mathrm{H}^{+}\right)_{s}=\mathrm{H}_{3} \mathrm{O}^{+}+\mathrm{NiO} \\
\mathrm{Ni}(\mathrm{OH})_{2}+2 \mathrm{H}^{+}=\mathrm{Ni}^{2+}+2 \mathrm{H}_{2} \mathrm{O}
\end{gathered}
$$

where $\left(\mathrm{H}^{+}\right)_{s}$ corresponds to a partially dehydrated hydrogen ion at the electrical double layer. Reaction $(7 \mathrm{~g})$ is the chemical dissolution of the $\mathrm{Ni}(\mathrm{OH})_{2}$ in the acid electrolyte. Furthermore, the NiO species can also be produced by the reaction:

$$
\left(\mathrm{NiOH}^{+}\right)=\left(\mathrm{H}^{+}\right)_{s}+\mathrm{NiO} .
$$

When reaction (7d) predominates over (7c) the passivation of the metal is due to the formation of $\mathrm{Ni}(\mathrm{OH})_{2}$ (prepassive state).

According to the reactions (7e) to $(7 \mathrm{~h})$, the rate of $\mathrm{Ni}(\mathrm{OH})_{2}$ formation should, therefore, compete with its chemical transformation and with its chemical dissolution. The relative contribution of each step in the overall process should depend on the characteristics of the potential perturbation. Furthermore, in the absence of any contribution by step $(7 \mathrm{f})$ the $\mathrm{Ni}(\mathrm{OH})_{2}$ formation entails a $\mathrm{pH}$ decrease at the reaction interface.

The current peak $\Pi$, has been justly assigned to the formation of a multi-layer of $\mathrm{Ni}(\mathrm{OH})_{2}$ causing the partial blockage of the electrode surface. Its characteristics 
as far as the shift of its potential during cycling is concerned, can easily be explained with the above mentioned reactions as due to the local $\mathrm{pH}$ change at the interface during the potential cycling to attain a stationary value. Otherwise, the shift of the corresponding peak potential becomes more noteworthy when the electrolyte is at rest. Stirring attenuates the effect as it tends to destroy the local pH gradient generated during the electrochemical processes (7a)-(7d). The limiting current which is observed at potentials immediately after the current peak $\Pi$ is congruent with a precipitationdissolution mechanism of $\mathrm{Ni}(\mathrm{OH})_{2}$ expressed through steps (7d) and (7g). As expected, that limiting current increases linearly either with $v^{1 / 2}$ or with $w^{1 / 2}$. This confirms the evidence for the formation of a prepassive film on $\mathrm{Ni}$ coming out from the current maxima observed in anodic polarization curves prior to passivation. ${ }^{28-30}$

At potentials more anodic than that of current peak $\Pi$, where the current peak I is observed, the species already formed are again either electrochemically or chemically transformed. The reactions can be put forward in terms of chemical compounds as follows:

$$
\begin{gathered}
\mathrm{Ni}(\mathrm{OH})_{2}=[\mathrm{NiOOH}]+\mathrm{H}^{+}+e^{-} \\
2[\mathrm{NiOOH}]=\left[\mathrm{Ni}_{2} \mathrm{O}_{3}\right]+\mathrm{H}_{2} \mathrm{O} .
\end{gathered}
$$

The brackets indicate surface species which although given in terms of a chemical stoichiometry are not straightforwardly comparable to the structure of molecular in homogeneous compounds.

These reactions occur only when the limit of the potential scan exceeds a certain potential $E_{p}$, which is very close to the equilibrium potential of step (7i). The apparent increase of current peak I on increasing $w$ should be actually assigned to the increase of the baseline of the processes occurring at lower potentials. The formation of $\left[\mathrm{Ni}_{2} \mathrm{O}_{3}\right]$ entails the onset of a $\mathrm{Ni}$ surface completely passivated, clearly observed during the returning potentials scan when $E>E_{p}$. When this has occurred a cathodization at potentials where a net $\mathrm{H}_{2}$ discharge and probably $\mathrm{Ni}$ electrodeposition are produced.

It is interesting to note that a small but net limiting current is observed in the -0.15 to $-0.25 \mathrm{~V}$ potential range, involving a total charge which at the most is of the order of a monolayer of an adsorbed species. That potential region includes the potential of zero charge of $\mathrm{Ni}$ and it seems reasonable to assume that electroreduction taking place there involves the $\left(\mathrm{NiOH}^{+}\right)$adsorbed species.

The sequence of reactions postulated to describe the potentiodynamic behaviour of the $\mathrm{Ni}$ /solution interface imply a set of single electron transfer steps together with chemical steps and the formation of three major reaction products, namely, $\mathrm{Ni}(\mathrm{OH})_{2}, \mathrm{NiO}$ and $\left[\mathrm{Ni}_{2} \mathrm{O}_{3}\right]$. The latter is the simplest way of indicating a $\mathrm{NiO}$ lattice involving hole formation or $\mathrm{Ni}(\mathrm{III})$ species into the lattice. ${ }^{31}$ Recent studies of X-ray photo-electron spectroscopy of $\mathrm{Ni}$ surfaces passivated in ca. $0.5 \mathrm{M} \mathrm{H}_{2} \mathrm{SO}_{4}{ }^{32}$ precisely revealed that the film in the passive region is composed of $\mathrm{NiO}$ and $\mathrm{Ni}(\mathrm{OH})_{2}$ the former acting as the passivating species. It should be mentioned, however, that a non-stoichiometric film involving either $\mathrm{Ni}$ (III) or holes in the $\mathrm{NiO}$ lattice remains unresolved by the usual optical methods of surface studies. ${ }^{33}$ 
$\mathrm{Ni}(\mathrm{OH})_{2}$ is present at the electrode in the active and prepassive regions. This compound, probably a porous one, has little if any passivating effect, a result which is clearly demonstrated by the anodic current exhibited by the returning $E / I$ voltammogram when the anodic potential limit is lower than $E_{p}$. Therefore, the electrode under this circumstance remains still active. The anodic reaction occurring during the anodic and the cathodic potential scan occur practically at the same potential, except for the shift due to the local $\mathrm{pH}$ change together with the current decrease provoked by the accumulation of the reaction product. The difference between the current peak potential recorded during the anodic scan and that observed during the cathodic scan becomes smaller when the difference between $E_{p}$ and $E \lambda$, the anodic limit of the potential scan is larger. These voltammograms show a good coincidence between the potential of null current with the corrosion potential of nickel as defined above. The Tafel line obtained from the positive branch of current peak II, under the present circumstances, approaches a slope very close to $R T / F$, as is often found under stationary $E / I$ measurements. This result might tentatively be expressed by the consecutive dissolution mechanism of the Bockris type (steps 7a-7c) if the adsorption of the ( $\mathrm{NiOH})$ species satisfies a Frumkin-type isotherm. ${ }^{34}$ Otherwise, the Tafel line obtained from the positive branch of current peak II of an $E / I$ profile including the potential region of current peak $I$ after the nth repetitive scan, exhibits an intermediate slope between $R T / F$ and $2 R T / F$. This indicates that the Tafel slope is sensitive to the state of the surface which is changing during the potentiodynamic potential cycling. Obviously when any anodic potential scan initiated from a potential where the passivating species is still present to some extent on the electrode a net decrease of the amount of charge related to current peak II will be observed.

According to the advanced interpretation of the electrode process, the active dissolution already occurs when the potential hardly exceeds $E_{r}$. Then, the reaction takes place on an electrode surface where $\mathrm{NI}(\mathrm{OH})_{2}$ and $\mathrm{NiO}$ are already formed, either electrochemically or chemically through the following possible chemical reactions

$$
\left(\mathrm{NiOH}^{+}\right)+\mathrm{H}_{2} \mathrm{O}=\mathrm{Ni}(\mathrm{OH})_{2}+\mathrm{H}^{+}
$$

and

$$
\left(\mathrm{NiOH}^{+}\right)=\mathrm{NiO}+\mathrm{H}^{+},
$$

which can also be conceived as equilibria markedly shifted towards the left at high $\mathrm{H}^{+}$ion concentration. The present results therefore agree with previous ideas that a precursor film of $\mathrm{Ni}(\mathrm{OH})_{2}$ was formed prior to passivity. ${ }^{35}$

\section{Consequences of the proposed structure of the metal surface}

When the anion adsorbability is low and the potential of the metal is positive with respect to the zero charge potential, the prevailing surface species entails an ionic character which can be expressed in terms of the $\left(\mathrm{NiOH}^{+}\right)$species. This means that the water molecules which become the main species responsible for the metal dissolution, prepassivation and passivation reactions should approach a minimum 
energy configuration involving a strong orientation of the dipole with the oxygen atom towards the covered metal surface. This can be schematically represented as:<smiles></smiles>

This structure turns the formation of $\mathrm{Ni}(\mathrm{OH})_{2}$ much easily through a deprotonation mechanism. The positive charged surface induces a repulsion of $\mathrm{H}^{+}$ions from the reaction interface.

When an anion which specifically adsorbs is present, the limiting structure attained tends to neutralize the positively charged surface, decreasing thus the watersurface interaction and so cancelling to a great extent the repulsion for the $\mathrm{H}^{+}$ions. Under these circumstances the second step during the dissolution reaction becomes

$$
(\mathrm{NiOH})+\mathrm{H}^{+}=\left(\mathrm{Ni}^{+}\right)+\mathrm{H}_{2} \mathrm{O}
$$

instead of step (7b). Therefore, the different reaction pathways required to explain the kinetic behaviour of $\mathrm{Ni}$ in acid solutions containing anions of different degree of adsorbability are congruent with a common structure of the inner part of the metal/ electrolyte interface. The conclusions of the present work also agree with the idea that the fixation of the first monolayer of oxygen coming from water plays a fundamental role in the passivation process. This hypothesis is consistent with the assumption that the incorporation or electrochemical decomposition of $\mathrm{SO}_{4}{ }^{2-}$ is not of great or of decisive importance in the process of passivation. ${ }^{36,37}$

\section{Other possible passivity onset}

During the anodic dissolution of $\mathrm{Ni}$ at high current densities in solutions with a high $\mathrm{SO}_{4}{ }^{2-}$ ion concentration it is possible, although not observed under the present circumstances, that the reaction interface becomes saturated with the product $\mathrm{NiSO}_{4}$. This would mean an appreciable polarization contribution of the ohmic-type in the potentiodynamic $E / I$ profiles. ${ }^{38}$ This effect might become more remarkable in $\mathrm{SO}_{4}{ }^{2-}$ ion containing solutions than in $\mathrm{Cl}^{-}$ion containing solutions, as the $\mathrm{NiSO}_{4}$ solubility is significantly lower than that of $\mathrm{NiCl}_{2}$. Besides, the insoluble solid compound, $\mathrm{NiSO}_{4}$, is probably a poorer electrical conductor than $\mathrm{NiCl}_{2}$, since, as derived from their standard formation enthalpy, the band gap of the former is appreciably higher than that of the latter. In the absence of $\mathrm{Cl}^{-}$ions a similar qualitative conclusion is arrived at if the surface becomes saturated by $\mathrm{Ni}(\mathrm{OH})_{2}$.

Acknowledgement-This work is part of the research program of the ECOMAR project sponsored by the SENID (Office for Research and Development, Argentine Navy) and the Consejo Nacional de Investigaciones Cientificas y Técnicas of Argentina.

\section{REFERENCES}

1. N. TANaka and R. Tamamushi, Electrochim. Acta 9, 963 (1964).

2. A. J. ARvía and D. PosadAs, in The Electrochemistry of the Elements, Vol. III, p. 212 (Ed. A. J. BARD). Marcel Dekker, New York (1975).

3. V. Brusic, in Oxides and Oxide Films, Vol. I, p. 1 (Ed. J. W. DigGLE). Marcel Dekker, New York (1972). 
4. J. R. Vilche and A. J. ARvía, Corros. Sci, 15, 419 (1975).

5. G. SUsSeK and M. Kestern, Corros. Sci. 15, 225 (1975).

6. M. KeSten, Corros. Sci. 14, 665 (1974).

7. T. TokUda and M. B. IVES, J. electrochem. Soc. 118, 1404 (1971); M. ZAMIN and M. B. IVES, Corrosion 29, 319 (1973); M. ZAMIN and M. B. IvEs, J. electrochem. Soc. 121, 1141 (1974).

8. H. J. Rätzer-SChejbe and H. G. Feller, Z. Metallkde 63, 351 (1972); Corros. Sci. 13, 11 (1973).

9. Z. Szklarska-Smialowska, Corros. Sci. 11, 209 (1971), ibid. 12, 527 (1972); Werkstoffe und Korros. 22, 780 (1971).

10. G. T. Burstein and G. A. Wright, Electrochim. Acta 20, 95 (1975).

11. C. J. Chatfield and L. L. Shreir, Corros. Sci. 12, 563 (1972).

12. B. MacDougall and M. Cohen, J. electrochem. Soc. 122, 384 (1975); ibid. 123, 191 (1976).

13. R. D. Armstrong and M. Henderson, J. electroanal. Chem. 39, 222 (1972).

14. L. N. Yagupol'skaya, Zasch. Metal. 13, 338 (1975).

15. D. G. Deriagina and E. N. Paleolog, Elektrokhimiya 11, 1003 (1975).

16. Ya. Kolotyrkin, Yu. A. Popov and Yu. V. Alekseev, Elektrokhimiya 9, 624 (1973); ibid. 9, 629 (1973).

17. N. A. Balashova, N. T. Gorokhova and S. A. Lilin, Elektrokhimiya 9, 666 (1973).

18. J. R. VILCHE and A. J. ARví, J. electrochem. Soc. 123, 1061 (1976).

19. G. Paus, A. J. Calandra and A. J. Arvía, Anal. Soc. Cient. Arg. 192, 35 (1971).

20. YA. M. KolotyrKIN, Zasch. Metal. 3, 131 (1967); Z. Elektrochem. 62, 50 (1958); J. electrochem. Soc. 108, 209 (1961).

21. M. Pourbaix, Atlas of Electrochemical Equilibria in Aqueous Solutions, Pergamon-CEBELCOR, Brussels (1966).

22. T. Markovic and M. Ahmedbasic, Werkstoffe und Korros. 16, 212 (1965); T. Markovic, Werkstoffe und Korros. 16, 570 (1965).

23. R. Piontelli and G. Serravalle, $Z$. Elektrochem. 62, 759 (1958).

24. R. Suhrman, J. M. Heras, L. Viscido de Heras and G. Wedler, Ber. Bunsenges physik. Chem. 68, 511 (1964); ibid. 68, 990 (1964).

25. J. O'M. Bockris, S. D. Argade and E. Gileadi, Electrochim. Acta 14, 1267 (1969).

26. I. O'M. Bockris, D. Drazic and A. L. DesPic, Electrochim. Acta 4, 325 (1961).

27. R. C. V. Piatti, A. J. Arvía and J. J. Podestä, Electrochim. Acta 14, 541 (1969).

28. N. Sato and G. Okamoto, J. electrochem. Soc. 110, 605 (1963); ibid. 111, 897 (1964).

29. D. L. Piron, E. P. Koutsoukos and K. Nobe, Corrosion 25, 151 (1969).

30 A. B. IJzermans, Corros. Sci. 10, 113 (1970).

31. A. Pigeaud, Ph.D. dissertation, University of Cincinnati, Ohio (1974).

32. T. Dickenson, A. F. Povey and P. M. A. Sherwood, Paper 173, 25th ISE Meeting, Zürich (1976).

33. G. Blondeau, M. Froelicher, M. Froment and A. Hugot-le Goff, Proc. Symp. on Oxide Electrolyte Interfaces (Ed. R. S. ALwITT). Electrochem. Soc. (Publ.), p. 215 (1973).

34. J. R. Vilche and W. J. LoRenz, Z. physik. Chem. 96, 251 (1975); Corros. Sci. 12, 785 (1972).

35. A. K. N. REDDY, B. RAO and J. O'M. BockrIs, J. chem. Phys. 42, 2246 (1965); J. O'M. Bockris, A. K. N. RedDY and B. RAO, J. electrochem. Soc. 113, 1133 (1966); A. K. N. RedDY and B. RAO, Can. J. Chem. 47, 2687 (1969).

36. R. P. Frankenthal, J. electrochem. Soc. 114, 542 (1967); ibid. 116, 580 (1969); ibid. 116, 1649 (1969); Electrochim. Acta 16, 1845 (1971).

37. J. Siejka, C. Cherki and J. Yahalom, J. electrochem. Soc. 119, 991 (1972); Electrochim. Acta 17, 2371 (1972).

38. M. G. Sustersic and A. J. Arvia, Anal. Asoc. quim. argent, in press. 